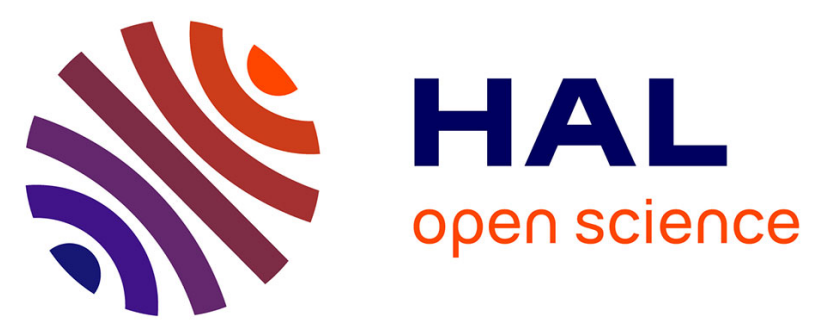

\title{
FeNO 7 -Type Halogenido Nitrosyl Ferrates: Syntheses, Bonding, and Photoinduced Linkage Isomerism
}

\author{
Areenan In-Iam, Markus Wolf, Claudia Wilfer, Dominik Schaniel, Theo \\ Woike, Peter Klüfers
}

\section{To cite this version:}

Areenan In-Iam, Markus Wolf, Claudia Wilfer, Dominik Schaniel, Theo Woike, et al.. FeNO 7 -Type Halogenido Nitrosyl Ferrates: Syntheses, Bonding, and Photoinduced Linkage Isomerism. Chemistry - A European Journal, 2019, 25 (5), pp.1304-1325. 10.1002/chem.201804565 hal-02101395

\section{HAL Id: hal-02101395 \\ https://hal.univ-lorraine.fr/hal-02101395}

Submitted on 16 Apr 2019

HAL is a multi-disciplinary open access archive for the deposit and dissemination of scientific research documents, whether they are published or not. The documents may come from teaching and research institutions in France or abroad, or from public or private research centers.
L'archive ouverte pluridisciplinaire HAL, est destinée au dépôt et à la diffusion de documents scientifiques de niveau recherche, publiés ou non, émanant des établissements d'enseignement et de recherche français ou étrangers, des laboratoires publics ou privés. 


\title{
$\{\text { FeNO }\}^{7}$-Type Halogenido Nitrosyl Ferrates: Syntheses, Bonding, and Photoinduced Linkage Isomerism
}

\author{
Areenan In-Iam, Markus Wolf, Claudia Wilfer, Dominik Schaniel, Theo Woike, Peter Klüfers*
}

\begin{abstract}
Mononitrosyliron compounds (MNICs) of the Enemark-Feltham $\{\mathrm{FeNO}\}^{7}$ type divide into a dublet $(S$ $=1 / 2)$ and a quartet $(S=3 / 2)$ spin variant. The latter relies on weak-field coligands such as aminecarboxylates. Aqua-only co-ligation appears to exist in the long-known 'brown-ring' $\left[\mathrm{Fe}\left(\mathrm{H}_{2} \mathrm{O}\right)_{5}(\mathrm{NO})\right]^{2+}$ cation which was prepared originally from ferrous salts and NO in sulfuric acid. A chloride variant of this species, the green $\left[\mathrm{FeCl}_{3}(\mathrm{NO})\right]^{-}$ion, was first prepared analoguosly by using hydrochloric instead of sulfuric acid. As a tetrahedral species, it is the simple prototype of sulfur-bonded $\{\mathrm{FeNO}\}^{7}(S=3 / 2) \mathrm{MNICs}$ of biological significance. Though being investigated for more than a century, neither clean preparative routes nor reliable structural parameters were available for the $\left[\mathrm{FeCl}_{3}(\mathrm{NO})\right]^{-}$ion and related species such as the $\left[\mathrm{FeCl}_{2}(\mathrm{NO})_{2}\right]^{-}$ion, a prototypical dinitrosyliron species (a 'DNIC'). In this work, both issues have been resolved. In addition, we report on a computational study on the ground- and excited-state properties including an assignment of the chromophoric transitions. Photoinduced metastable isomers were characterised in a combined experimental and computational approach which resulted in the confirmation of a single photoinduced linkage isomer of the paramagnetic nitrosyl-metal coordination entity.
\end{abstract}

\section{Introduction}

\section{Breaking the $\mathrm{Fe}-\mathrm{NO}$ bond: NO release vs. linkage isomerism}

Due to their biological significance in nitric-oxide metabolism, nitrosyl-iron complexes, both naturally occuring species as well as artificial agents, are a focus of current research. The infusion of an aqueous solution of pentacyanidonitrosylferrate (2-) dihydrate, $\mathrm{Na}_{2}\left[\mathrm{Fe}(\mathrm{CN})_{5}(\mathrm{NO})\right] \cdot 2 \mathrm{H}_{2} \mathrm{O}$, has been a longknown method to administer the vasodilator NO during surgery. Besides the medical application, the solid dihydrate ('SNP' from the salt's common name 'sodium nitroprusside') has attracted much interest since half a century ago, when long-lived metastable states had been produced by irradiation with green laser light at low temperatures. Two decades after their discovery, the formation of linkage isomers of the nitrosyl ligand was detected by means of photocrystallography as the origin of the phenomenon. ${ }^{[1]}$ Specifically, two metastable isomers formed in the course of the relaxation of the electronically excited states, namely a $\kappa O$ bonded isonitrosyl (MS1), and a $\kappa^{2} N, O$-bonded side-on nitrosyl (MS2). Photoinduced linkage isomerism (PLI) is neither restricted to the low-temperature regime of metastability nor to the solid state. Short-lived linkage isomers of SNP have been detected at room temperature in the solid as well as in aqueous solution. ${ }^{[2]}$ Consequently, PLI or, more generally, linkage isomerism, was also considered to play a role in physiological NO metabolism. ${ }^{[3]}$

There is a notable point which specifically applies to the physiological $\mathrm{Fe}(\mathrm{NO})$ species. Most currently known PLI-active systems, either based on iron or another central metal, have diamagnetic ground states. $\mathrm{SNP}$ is an example. A singlet, low-spin- $\mathrm{d}^{6} \mathrm{Fe}^{\mathrm{II}}$ centre bonds to a ${ }^{1} \mathrm{NO}^{+}$ligand via the classical donor-acceptor bonding scheme with the NO-releasing property of SNP solutions going along with the limited back-bonding capability of an iron centre of the rather high oxidation state II. A rare exception to this experience was the report by Chen et al. who succeeded in the population of an MS1 state for the paramagnetic nitrosyl complex 
of a heme model complex, a member of the $\left\{\mathrm{FeNO}^{7}(S=1 / 2)\right.$ subclass (see the following subsection for the nomenclature) ${ }^{[4]}$

An obvious reason for the preference for singlets is not known. Perhaps we may assume that the metastable isomers are protected by activation barriers along spin-forbidden relaxation paths. ${ }^{[2 \mathrm{~d}]}$ (Note, in this context, the interesting case of coupling a PLI and a spin-crossover event, where a low-spin, singlet ground state was photo-excited to a high-spin isomer. ${ }^{[5]}$ )

\section{$\{\text { FeNO }\}^{7}$ species}

In our own work, we experienced the lack of PLI phenomena in one subclass of mononitrosyliron compounds of the $\{\mathrm{FeNO}\}^{7}$ type (in this Enemark-Feltham notation, read " 7 " as the sum of metal-d and NO$\pi^{*}$ electrons, i.e., $7+0$ for $\mathrm{Fe}^{\mathrm{I}}+\mathrm{NO}^{+}$, or $6+1$ for $\mathrm{Fe}^{\mathrm{II}}+\mathrm{NO}$, or $5+2$ for $\mathrm{Fe}^{\mathrm{III}}+\mathrm{NO}^{-}$). $\{\mathrm{FeNO}\}^{7}$ centres are found with an $S=1 / 2$ ground state, in heme-NO adducts for example (see above), or in the $S=3 / 2$ spin state. The latter spin state occurs with weak-field co-ligands such as aminecarboxylates, or, in a biochemical environment, with sulfur-derived ligands such as cysteinate or ferredoxin-bound sulfide (see the next subsection). Recently, we published a number of crystalline aminecarboxylate-coligated octahedral $\{\mathrm{FeNO}\}^{7}(S=3 / 2)$ complexes where we attempted to populate photoinduced isomers in those solids in the typical temperature and excitation-energy range which yielded metastable isomers in the case of SNP. ${ }^{[6]}$ However, we did not detect isomers in terms of IR spectra. For a closer approach to the problem, we continued the search for PLI-active species at lower temperatures. As a starting point for this investigation, we chose members of the class of tetracoordinate nitrosyl-iron compounds - a class that had attracted particularly long-standing interest in the history of chemical science.

\section{MNICs and DNICs}

Tetracoordinate mononitrosyl irron compounds ('MNICs') as well as their dinitrosyl homologues ('DNICs') have been a topic of research for decades. Currently, the focus lies on thiolato- and sulfido-ligated nitrosyl-iron species, due to their role in signalling and metabolic pathways. ${ }^{[7]}$ Examples include thiolatosupported MNICs and DNICs with alkyl- and arylthiolates as well as the proteinogenic $\mathrm{RS}^{-}$donor cysteinate. ${ }^{[7 b]}$ The replacement of sulfido ligands on the exposure of $[2 \mathrm{Fe}-2 \mathrm{~S}]$ clusters to nitric oxide in the presence of chloride has recently provided one more route to the longest-known members of the MNIC and DNIC class: the halogenido nitrosyl iron compounds. ${ }^{[7 b]}$ With their simple formula, monoanions such as $\left[\mathrm{FeCl}_{3}(\mathrm{NO})\right]^{-}$and $\left[\mathrm{FeCl}_{2}(\mathrm{NO})_{2}\right]^{-}$may be regarded as parent species of the MNIC and DNIC type, respectively. The long-standing interest that these species have attracted is documented in over a century of publications on the mononitrosyls, from Kohlschütter's synthetic route in aqueous acid in 1904 to van Eldik's preparation in ionic liquids in $2015 .{ }^{[8]}$ Throughout this entire period, however, a constant feature of this chemistry has impeded the efforts of the various groups to safely detect those species, namely the lack of reliable basic information on isolated, pure, and well-characterised salts of those anions - though various attempts have been made.

\section{History: 'brown-ring' variations}

In a first period of research, the competing groups of Kohlschütter and Manchot contended for the clarification on the constitution to be assigned to the 'brown-ring' species of nitrate and nitrite analysis, now usually formulated as $\left[\mathrm{Fe}\left(\mathrm{H}_{2} \mathrm{O}\right)_{5}(\mathrm{NO})\right]^{2+}$. In 1904 and 1907, Kohlschütter published on a green, anionic variant of the tentative nitrosyl species that he had observed on NO absorption in a ferrous chloride solution in concentrated hydrochloric acid. With his formulation of the green species as the anion of a 
'Ferrochlorwasserstoffsäure' [chloridoiron(II) acid], Kohlschütter was one of the first to use the emerging ideas of coordination chemistry. ${ }^{[8 a, 9]}$ In 1911, Kohlschütter summarised the state of knowledge and formulated the green species as $\left[\mathrm{FeCl}_{2+x}(\mathrm{NO})\right]^{\prime x}$ (Kohlschütter was not able to isolate crystalline substances; hence, lacking elemental analyses, he could only speculate on $x$ which he guessed was two in an attempt to interpret the formation of an anionic species in the electrolysis of an $\mathrm{FeCl}_{2} / \mathrm{NO}$ solution in ethanol). ${ }^{[10]}$ In the same period of time, Manchot prepared a green anion by the reaction of ferric chloride and nitric oxide in organic solvents such as ethanol. ${ }^{[11]}$ He stated the identity of the green products from both ferrous and ferric chloride, and he identified nitric oxide as the reductant, but he could not give a full reaction equation (he suspected complicated side reactions of the organic part).

UV-vis spectroscopy was available some two decades later, ${ }^{[12]}$ and, another three decades later, the $S=$ $3 / 2$ ground state of the related aqua species was determined. ${ }^{[13]}$ Remarkably, in the latter work, Griffith et al. reported on a (non-isolated), green(!) ferric analogue of the tentative formula $\left[\mathrm{Fe}(\mathrm{EtOH})_{5}(\mathrm{NO})\right]^{3+}$ from the reaction of ferric chloride in ethanol with NO gas. Hence, the authors de facto reproduced Manchot's experiment but arrived at different conclusions about the formula of the green chromophore. A motif might have been that the magnetic moment of the species exceeded the expected value for a high-spin $\{\mathrm{FeNO}\}^{7}$ compound. It should be noted, however, that the reported value for the $\mathrm{N}-\mathrm{O}$ stretch $\left(1775 \mathrm{~cm}^{-1}\right.$ in EtOH solution) was consistent with later reported values for the $\left[\mathrm{FeCl}_{3}(\mathrm{NO})\right]^{-}$ion (compare $1798 \mathrm{~cm}^{-1}$ in a solution with the $\mathrm{NEt}_{4}{ }^{+}$counterion in $\mathrm{MeOH}$ ).

In the 1960s, the arrival of ESR spectroscopy restarted the investigation of the reaction of ferrous salts including the halogenides with NO ('restarted' meaning that the authors in this period ignored Kohlschütter's work) ${ }^{[14]}$ Synthetic protocols included the use of methanol as the solvent and, mostly, the addition of a base such as triethylamine. ${ }^{[15]}$ As a result, the respective chlorido-DNIC and an alkyl nitrite formed in solution instead of an MNIC, tentatively according to the equation:

$$
\mathrm{FeCl}_{2}+3 \mathrm{NO}+\mathrm{MeOH}+\mathrm{NEt}_{3} \rightarrow \mathrm{NHEt}_{3}\left[\mathrm{FeCl}_{2}(\mathrm{NO})_{2}\right]+\mathrm{MeONO}
$$

The bromido-DNIC was prepared in a similar procedure. ${ }^{[16]} \mathrm{A}$ specification is necessary at this point. This work includes DNICs that were formed in competition with $\left\{\mathrm{FeNO}^{7}(S=3 / 2)\right.$ MNICs. In EnemarkFeltham notation, these belong to the $\left\{\mathrm{Fe}(\mathrm{NO})_{2}\right\}^{9}$ class with a total spin of $S=1 / 2$.

In the subsequent organometallic era, work on halogenido-nitrosyl ferrates emerged that did not refer to all these prior findings but looked at the green variant as an analogue of halogenido-carbonyl species. Following standard organometallic procedures, aprotic routes were thus used to prepare various halogenidonitrosyl ferrates. In 1976, the Connelly group reported the preparation and the IR-spectroscopic characterisation of a green $\mathrm{PPN}\left[\mathrm{FeCl}_{3}(\mathrm{NO})\right]$ which formed on an oxidative route by the reaction of $\mathrm{PPN}\left[\mathrm{Fe}(\mathrm{CO})_{3}(\mathrm{NO})\right]$ with $\mathrm{Cl}_{2}$ in dichloromethane [PPN = bis(triphenylphosphaneiminium) $]$ via

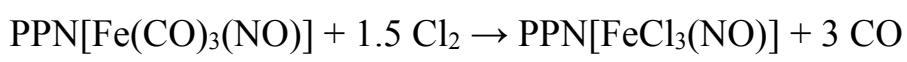

However, due to the strongly oxidising chlorine reagent, the authors described unexpected magnetic moments of their products which they attributed to ferric by-products. The carbonylferrate educt was transformed by the heavier halogens in similar reactions to the bromido-MNIC/DNIC as well as to the iodido-DNIC. ${ }^{[17]}$

In 1983, the Beck group reported the crystal structure of an $\mathrm{AsPh}_{4}\left[\mathrm{FeCl}_{3}(\mathrm{NO})\right]$ which had formed on their attempts to prepare and isolate a salt of the DNIC homologue $\left[\mathrm{FeCl}_{2}(\mathrm{NO})_{2}\right]^{-}$by reacting Roussin's red salt with $\mathrm{HCl}$ gas in pentane. Unexpected by the authors, the isolated crystals turned out to be the trichlorido- 
mononitrosyl ferrate in the course of the structure determination by means of Weissenberg film techniques. Irritatingly, not a green, but a DNIC-typical red-brown colour of the crystals was reported. More recently, Akutsu et al. repeated Beck's work with some modifications and isolated crystals of the claimed formula $\mathrm{PPh}_{4}\left[\mathrm{FeCl}_{2}(\mathrm{NO})_{2}\right]$ whose anion is the one that Beck attempted to prepare. The characterisation of the needles, which were reported as isostructural to Beck's, however, was ambiguous: the crystals were brown (DNIC), the X-ray analysis revealed $\mathrm{Cl} / \mathrm{NO}$ disorder, and the magnetism showed parameters closer to the MNIC rather than the attempted DNIC ${ }^{[18]}$ Coincidental with Akutsu's work, the Lippard group published a crystal-structure determination on a cationic MNIC with the $\left[\mathrm{FeCl}_{3}(\mathrm{NO})\right]^{-}$ion as the counterion stemming from the dismutation of a $\mathrm{FeCl}_{2}$ precursor. Also in that work, it is the halogenido-MNIC that caused some ambiguity in terms of an unresolved residual electron density of $2.5 \mathrm{e} \AA^{-3}$ within the anion. ${ }^{[19]}$ Eventually, the most recent crystal-structure analysis that included the $\left[\mathrm{FeCl}_{3}(\mathrm{NO})\right]^{-}$ion revealed disorder in this species. ${ }^{[20]}$

While no isolated fluorido-nitrosyl-iron compounds have been published, some data are available on bromido and iodido derivatives. In particular, an X-ray structure analysis on single crystals of the iodidoDNIC is known, namely PPN[FeI $\left.2(\mathrm{NO})_{2}\right] .{ }^{[21]}$ No structural information has been published on $\mathrm{A}\left[\mathrm{FeBr}_{3}(\mathrm{NO})\right]$ and $\mathrm{A}\left[\mathrm{FeBr}_{2}(\mathrm{NO})_{2}\right]$ salts.

For the focus of this work, the $\left[\mathrm{FeCl}_{3}(\mathrm{NO})\right]^{-}$ion, the preparative situation had to be clarified first. In fact, the literature provides no reliable route for the preparation of an isolated salt of this prototypical nitrosyl complex: Connelly's and Gardner's oxidation of carbonyl precursors by $\mathrm{Cl}_{2}$ resulted in $\mathrm{Fe}^{\mathrm{III}}$-contaminated samples. The more direct methods that start with simple ferrous salts in protic media including water seem to be impeded by the need to match the stability fields of MNICs and DNICs. Thus, chlorido-MNICs may be captured in acidic media, whereas chlorido-DNICs are preferentially formed in less acidic to basic solution. This rule of thumb becomes obvious when comparing the reaction of ferrous chloride with NO gas yielding $\left[\mathrm{FeCl}_{3}(\mathrm{NO})\right]^{-}$in hydrochloric acid on the one hand, and the formation of $\left[\mathrm{FeCl}_{2}(\mathrm{NO})_{2}\right]^{-}$in methanol/trialkylamine instead of $\mathrm{HCl}(\mathrm{aq})$ on the other. In the light of stability fields, the problems encountered in Beck's approach to chlorido-DNICs via the hydrolysis of thio-DNICs with hydrochloric acid become tangible. (The rules apply to the chlorido systems; bromide and iodide form DNICs more easily.) Thus, the focus of this work lies on the preparation of pure, crystalline halogenido-nitrosyl ferrates as a prerequisite for reliable structure analyses and physical measurements on well-defined members of this rather fundamental substance class.

Our report is organised as follows: (1) The aptitude of the oldest route by Kohlschütter for the preparation of pure trichloridonitrosylferrate(II) from $\mathrm{FeCl}_{2}$ and $\mathrm{NO}$, free of iron(III) and dinitrosylferrates, is demonstrated. The route is modified to yield a crystalline salt. (2) The solvent is changed from water or hydrochloric acid to methanol and the preparation of salts with a variety of cations is employed. (3) Ferric salts are demonstrated to yield the $\left[\mathrm{FeCl}_{3}(\mathrm{NO})\right]^{-}$ion as well but ferric contaminations of the product crystals have to be monitored carefully. (4) The shift of the isolated product from the mononitrosyl to the dinitrosyl species, if the reaction is conducted in the presence of base, is investigated. In this part, $\mathrm{NO} /$ halogenide disorder is analysed as well. (5) Since the chlorido-nitrosyl ferrates are particularly small entities, computational methods in both the frameworks of density functional and wave-function theory were employed to analyse bonding and spectra of these species. (6) Two types of photoexcited metastable MNIC products were produced and characterised by their $\mathrm{N}-\mathrm{O}$ valence frequency: the isonitrosyl (MS1) isomer and the neutral $\mathrm{FeCl}_{3}(\mathrm{NO})$ photooxidation product. The lack of an MS2 isomer will be rationalised by a DFT analysis. (6) Analogies in the DNIC field are carved out in a more summarising way. 


\section{Results and Discussion}

\section{Chemistry: preparative routes and route-dependent by-products}

\section{History I (1904-1911): Pure green $\mathrm{AsPh}_{4}\left[\mathrm{FeCl}_{3}(\mathrm{NO})\right]$ from Kohlschütter's aqueous route ${ }^{[8 \mathrm{a}, 9-10]}$}

In the first decade of the 20th century, Kohlschütter obtained green solutions from the reaction of ferrous chloride and nitric oxide in hydrochloric acid. ${ }^{[8 a, 9]}$ This earliest investigator, however, did not succeed in synthesising crystals of his green variant of the brown-ring species which he obtained by the replacement of sulfuric by hydrochloric acid in the nitrosation of ferrous solutions. In fact, crystals can be obtained with a bulky counterion by carefully balancing educt and product solubilities. Hence, monoclinic green crystals of $\mathrm{AsPh}_{4}\left[\mathrm{FeCl}_{3}(\mathrm{NO})\right]$ were obtained from solutions of ferrous chloride and tetraphenylarsonium chloride in hydrochloric acid/methanol on the slow addition of nitric oxide to a nitrogen atmosphere above the liquid without stirring. The green chromophore, the anion, is depicted in Figure 1. It resembles Kohlschütter's $\left[\mathrm{FeCl}_{2+x}(\mathrm{NO})\right]^{\prime x}$ formulation for $x=1 .{ }^{[10]}$ Moreover, it resembles Connelly's anion in terms of colour and IR data, and Beck's red-brown anion in terms of structure.

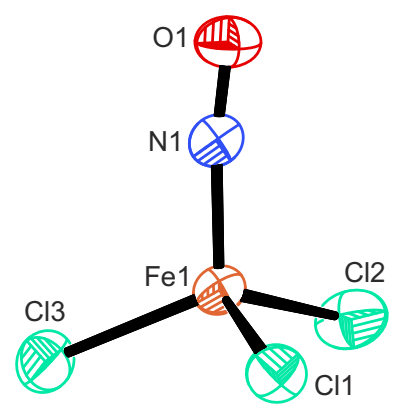

Figure 1. The structure of the anion in monoclinic crystals of $\mathrm{AsPh}_{4}\left[\mathrm{FeCl}_{3}(\mathrm{NO})\right](50 \%$ ellipsoid probability). Distances (in $\AA$ ) from Fe1 to: Cl1 2.232(1), Cl2 2.229(1), Cl3 2.233(1), N1 1.730(4); N1-O1 1.142(5). Angles (in degrees): Fe1-N1-O1 171.6(4), Cl1-Fe1-N1 108.5(1), Cl2-Fe1-N1 105.0(1), Cl3-Fe1-N1 112.2(1); mean $\mathrm{Cl}-\mathrm{Fe} 1-\mathrm{Cl} 110.4$.

A closer look at the crystal structure shows traces of pseudosymmetry. If the small offset of the cation and anion centres from the 2 axis is removed, the monoclinic angle $\left(90.5^{\circ}\right)$ is set to $90^{\circ}$, and the $a$ and $c$ axis lengths (12.89 and $13.28 \AA$ ) are set as equal, an idealised tetragonal structure results in the supergroup $P 4 / n$ $\left(c_{\text {tetragonal }}=1 / 2 b_{\text {monoclinic }}\right)$ of the actual space group $P 21 / n$. We will use this information later in the discussion of Beck's structure. At this point, a modified Kohlschütter route appeared to be suitable for the preparation of pure trichlorido-nitrosyl-ferrates.

\section{History II (1910 and 1958): Manchot's and Griffith's green solutions starting from ferric chloride $\mathrm{e}^{[11,13]}$}

Both the green colour and the IR spectrum led us to the educated guess that Griffith et al. had the same product in their hands that had been prepared by Manchot half a century earlier using exactly the same route, namely the $\left[\mathrm{FeCl}_{3}(\mathrm{NO})\right]^{-}$ion. Since the only candidate for the required reductant was, as was already assumed by Manchot, nitric oxide, the reaction would have to proceed according to the equation:

$\mathrm{FeCl}_{3}+2 \mathrm{NO} \rightarrow\left[\mathrm{FeCl}_{3}(\mathrm{NO})\right]^{-}+{ }^{-} \mathrm{NO}^{+}$,

' $\mathrm{NO}^{+}$' had to be replaced by a respective secondary product; in the case of EtOH as the solvent, ethyl nitrite formation might be considered. It should be noted that the iron(III) reduction by NO under alkyl nitrite formation was recently demonstrated by the Lehnert group in the course of DNIC formation. ${ }^{[22]}$ Under 
Griffith's reaction conditions, however, residual ferric species seemed to contaminate the tentative ferrous nitrosyl complex in terms of a magnetic moment reported that was too high for the pure product. Attempts to reproduce the experiments confirmed the reported observations. Since the entire reaction path is better understood after a discussion of our attempts to reproduce the remaining historic routes, the iron(III) issue will be re-addressed and clarified below.

\section{History III (1976): Connelly's green, iron(III)-contaminated PPN $\left[\mathrm{FeX}_{3}(\mathrm{NO})\right]$ solids $(\mathrm{X}=\mathrm{Cl}, \mathrm{Br})^{[17]}$}

Connelly and Gardner prepared $\mathrm{PPN}\left[\mathrm{FeCl}_{3}(\mathrm{NO})\right]$, a dark green solid, by the reaction of $\mathrm{PPN}\left[\mathrm{Fe}(\mathrm{CO})_{3} \mathrm{NO}\right]$ with chlorine in dichloromethane. ${ }^{[17]}$ The reported values, an $S=3 / 2$ state for the anion as well as an $\mathrm{N}-\mathrm{O}$ stretch at $1802 \mathrm{~cm}^{-1}$, suggest the identity of the anion with the one obtained by the Kohlschütter procedure. Since no crystal-structure analysis was available, we reproduced Connelly's recipe and crystallised the green product. As a result, the expected anion was the major disorder species of the green solid. In addition to the major NO site, however, an approximately $13 \%$, minor disorder form was detected where the NO ligand was replaced by a chlorine atom. The crystallographic result indicated that the cocrystallisation of the $\left[\mathrm{FeCl}_{3}(\mathrm{NO})\right]^{-}$and the oxidised $\left[\mathrm{FeCl}_{4}\right]^{-}$species had taken place (for details of the X-ray analysis of contaminated samples see Figure 5 and the text referring to the figure).

The formation of the tetrachloridoferrate(III) side product thus appeared as a drawback of Connelly's oxidative route. It should be noted that the amount of side product in our structure analysis corresponded to the result of Connelly's elemental analysis that showed a nitrogen deficiency of about $10 \%$. A specific point that is re-addressed below should be noted here: recrystallisation does not appear to be a reliable method for the separation of equally charged nitrosyl and chlorido species. Instead, nitrosyl and chlorido ligands appear to tend towards mutual replacement. Due to the small amount of tetrachloridoferrate(III) in the investigated crystal, however, the parameters of the major species were sensible and were close to those collected in the caption of Figure 1.

\section{History IV (1983): Beck's red-brown, DNIC-containing $\mathrm{AsPh}_{4}\left[\mathrm{FeCl}_{3}(\mathrm{NO})\right]^{[23]}$}

To give an explanation for Beck's result that $\mathrm{AsPh}_{4}\left[\mathrm{FeCl}_{3}(\mathrm{NO})\right]$ should form dark red-brown instead of green crystals was more challenging. Attempts to reproduce Beck's recipe confirmed the published results. Just as the Beck group, we obtained a dark red-brown solid that showed the bulk characteristics of the attempted $\mathrm{AsPh}_{4}\left[\mathrm{FeCl}_{2}(\mathrm{NO})_{2}\right]{ }^{[24]}$ The solid was uniform in terms of colour. Moreover, two isolated, dark redbrown crystals showed the reported tetragonal unit cell. ${ }^{[23]}$ The structure determination ended as the published one with large thermal ellipsoids for almost all atoms, in particular for two of the chlorine atoms. Attempts to establish an $\mathrm{NO} / \mathrm{Cl}$ disorder refinement to model the admixture of the monoanionic $\left\{\mathrm{Fe}(\mathrm{NO})_{2}\right\}^{9}{ }^{-}$ DNIC $\left[\mathrm{FeCl}_{2}(\mathrm{NO})_{2}\right]^{-}$on the anion site failed. The failure was unexpected since even small amounts of $\left[\mathrm{FeCl}_{4}\right]^{-}$in both Connelly-type and other (see below) samples were safely detected on the level of contemporary diffractometer data sets. To this end, we concluded from the colour of the samples that MNIC/DNIC co-crystallisation had taken place, with the result that the 1983 method should not be applied for the preparation of pure MNIC samples for physical measurements.

This result has been supplemented by a recent structure determination by Akutsu et al. on isostructural crystals with the $\mathrm{PPh}_{4}{ }^{+}$counterion. ${ }^{[18]}$ The authors used the Beck method for the preparation of a salt of the claimed formula $\mathrm{PPh}_{4}\left[\mathrm{FeCl}_{2}(\mathrm{NO})_{2}\right]$. The report, however, shows all the problems mentioned: severe $\mathrm{NO} / \mathrm{Cl}$ disorder in the structure analysis, and a magnetic moment which is clearly closer to the $S=3 / 2$ spin of the $\{\mathrm{FeNO}\}^{7}$ trichlorido-MNIC than to the $S=1 / 2$ spin of the claimed $\left\{\mathrm{Fe}(\mathrm{NO})_{2}\right\}^{9}$ dichlorido-DNIC. 


\section{A standard route to pure $\left[\mathrm{FeCl}_{3}(\mathrm{NO})\right]^{-}$and $\left[\mathrm{FeBr}_{3}(\mathrm{NO})\right]^{-}$salts with various cations}

For the most convenient approach to chlorido- and bromido-MNICs, the modified Kohlschütter route which was used for the preparation of crystalline $\mathrm{AsPh}_{4}\left[\mathrm{FeCl}_{3}(\mathrm{NO})\right]$, was further generalised. As a result, pure, crystalline trichlorido- as well as tribromidonitrosylferrates of various, more or less bulky cations were prepared by a facile procedure which uses inexpensive educts (ferrous chloride tetrahydrate or ferrous triflate and a bromide, the chloride or bromide of the desired counterion, degassed methanol as the solvent, and an excess of purified, i.e. $\mathrm{NO}_{2}$-free, nitric oxide) at ambient conditions. The procedure follows the equation (for the chloride):

$$
\mathrm{A}^{+} \mathrm{Cl}^{-}+\mathrm{FeCl}_{2}+\mathrm{NO} \rightarrow \mathrm{A}^{+}\left[\mathrm{FeCl}_{3}(\mathrm{NO})\right]^{-}
$$

The water content of the tetrahydrate employed did not interfere nor was there need to limit NO dosage. The reaction's progress was easily monitored by the deepening of the characteristic green colour. The typical time for $\mathrm{NO}(\mathrm{g})$ exposure was about $2-10 \mathrm{~min}$ ( $2 \mathrm{~min}$ for a newer apparatus with quick inert-gasNO displacement, $10 \mathrm{~min}$ for an older one with a somewhat slower displacement). The yield of isolated crystalline product reached $90 \%$ for the larger counterions $\mathrm{PPh}_{4}{ }^{+}, \mathrm{AsPh}_{4}{ }^{+}$, and $\mathrm{PPN}^{+}$. All solids were stable to air for months, thus no special care had to be taken for investigating them. This property should be mentioned since the mother liquors belong to the low-stability class defined in Ref. ${ }^{[6 b]}$ which means that purging the solutions with a stream of inert gas will destroy the nitrosyl complex rapidly by reversing its formation reaction. Seeding and growing crystals thus was performed under an NO atmosphere throughout this work.

All the photophysical measurements decribed below were conducted on samples from this standard procedure, the only exception being the special cobaltocenium case (see the next subsection).

For the $\left[\mathrm{FeCl}_{3}(\mathrm{NO})\right]^{-}$anion, well-ordered crystal structures were found with the counterions $\mathrm{NMe}_{4}^{+}$, $\mathrm{NEt}_{4}{ }^{+}, \mathrm{NBnMe}_{3}{ }^{+}(\mathrm{Bn}=$ benzyl $), \mathrm{Mephaz}^{+}(5$-methyl-phenazinium $), \mathrm{PPh}_{4}{ }^{+}, \mathrm{AsPh}_{4}{ }^{+}, \mathrm{PPN}^{+}=$ bis(triphenylphosphaneiminium).

With ferrous triflate and the threefold molar amount of the bromide of the counterion, $\mathrm{A}^{+} \mathrm{Br}^{-}$, the standard route yielded the respective salts of the homologous $\left[\mathrm{FeBr}_{3}(\mathrm{NO})\right]^{-}$anion. This variant was used for the preparation of well-ordered crystals with $\mathrm{PPh}_{4}{ }^{+}$or $\mathrm{AsPh}_{4}{ }^{+}$as the counterions. These crystal-structure analyses were the first of a salt of the bromido-MNIC. The result is shown for the PPN salt in Figure 2. Further details of both analyses are collected in the SI.

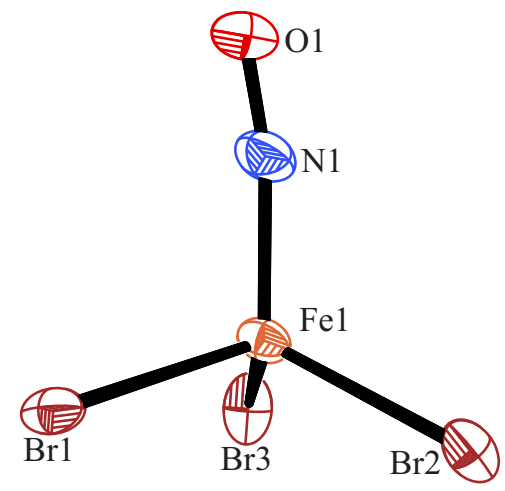

Figure 2. The structure of the anion in monoclinic crystals of $\mathrm{PPN}\left[\mathrm{FeBr}_{3}(\mathrm{NO})\right](50 \%$ ellipsoid probability). Distances (in §̊) from Fe1 to: Br1 2.3657(5), Br2 2.3755(6), Br3 2.3843(6); Fe1-N1 1.729(3), N1-O1 1.150(3). Angles (in degrees): Fe1-N1-O1 169.5(3); mean Br-Fe1-Br 109.7. 
Attempts to synthesise salts of an unknown $\left[\mathrm{FeI}_{3}(\mathrm{NO})\right]^{-}$anion failed. Nitrosylation of iodidecontaining solutions always yielded the respective DNIC $\left[\mathrm{FeI}_{2}(\mathrm{NO})_{2}\right]^{-}$.

The term "well-ordered" has been stressed repeatedly. The criteria applied include the usual numbers of merit of an X-ray experiment, and, in addition, $\mathrm{Fe}-\mathrm{N}$ and $\mathrm{N}-\mathrm{O}$ distances within a narrow range. As a typical example, Figure 7 in a later section includes the parameters for $\mathrm{Mephaz}^{+}\left[\mathrm{FeCl}_{3}(\mathrm{NO})\right]^{-}$. Crystallographic data for the other salts are collected in the SI.

\section{The reduction of ferric educts by a reduced counterion}

In the case of the one-electron reductant cobaltocene, $\left[\mathrm{Co}(\mathrm{cp})_{2}\right]$, a variant of the standard procedure which appears to be applicable if the reduced form of the counterion is available, was successful. Starting with ferric instead of ferrous chloride, the attempted product was obtained according to the equation:

$$
\left[\mathrm{Co}(\mathrm{cp})_{2}\right]+\mathrm{FeCl}_{3}+\mathrm{NO} \rightarrow\left[\mathrm{Co}(\mathrm{cp})_{2}\right]^{+}\left[\mathrm{FeCl}_{3}(\mathrm{NO})\right]^{-}
$$

The reduction of iron(III) was complete in terms of the structural data of the product which thus appeared free of ferric contaminants. Details of the X-ray analysis are listed in the SI. The motif to prepare a salt with a reducible cation is commented in the physics part below.

\section{The reduction of ferric educts by NO}

Utilising the observations reported by Manchot and Griffith, we replaced the ferrous chloride component of the standard procedure with ferric chloride. ${ }^{[11,13]}$ In methanol, ferric chloride was transformed to the $\left[\mathrm{FeCl}_{3}(\mathrm{NO})\right]^{-}$ion by $\mathrm{NO}(\mathrm{g})$ as the reductant according to the equation:

$$
\mathrm{A}^{+} \mathrm{Cl}^{-}+\mathrm{FeCl}_{3}+2 \mathrm{NO} \rightarrow \mathrm{A}^{+}\left[\mathrm{FeCl}_{3}(\mathrm{NO})\right]^{-}+\mathrm{MeONO}+\mathrm{HCl}
$$

The formation of methyl nitrite is best monitored by UV-vis spectroscopy where a characteristic 'fivefinger' motif indicated MeONO formation (see the SI).

Even for the smaller counterions, the crystallisation often proceeded more quickly than in the case of the respective standard ferrous route. A typical case is the tetraethylammonium counterion. The ferrous route yielded green solutions, as usual, but, in great contrast to a large counterion such as $\mathrm{PPN}^{+}$, no crystals precipitated from them for months. Eventually, green crystals seeded after about a year. The same experiment on the ferric route resulted in the seeding and growth of green $\mathrm{NEt}_{4}\left[\mathrm{FeCl}_{3}(\mathrm{NO})\right]$ crystals from cooled mother liquors within about two weeks.

At first glance, the structure analysis on $\mathrm{NEt}_{4}\left[\mathrm{FeCl}_{3}(\mathrm{NO})\right]$ crystals from the ferric route was inconspicuous in terms of the usual figures of merit such as $\mathrm{R}$ values or residual electron densities. However, the analysis shared a common peculiarity with the analyses on other crystals from the ferric route with various counterions, namely an atypical long $\mathrm{Fe}-\mathrm{N}$ and a shortened $\mathrm{N}-\mathrm{O}$ bond. The origin of this observation on the ferric variant of the standard ferrous route will be resolved in the Crystallographic Section.

The anomaly can be remedied by a variation of the conditions, namely dilution to about one tenth of the standard concentration. This alteration yielded pure crystals of the target compounds with unsuspicious $\mathrm{X}$-ray parameters. However, the ferric route then becomes unattractive from a practical viewpoint. Yields were low, and a long crystallisation time for small counterions as typical for the ferrous route, resulted. 


\section{Consecutive MNIC-to-DNIC transformation in the presence of base}

Towards a standard route to dichlorido-DNICs

The reliability of the standard and the ferric procedure to yield either pure or $\mathrm{Fe}^{\mathrm{III}}$-contaminated MNICs depends on the absence of base. Various publications from the second half of the last century reported the formation of DNICs if base was added to the otherwise identical reaction mixtures. ${ }^{[14,16]} \mathrm{An}$ example is the report of Gwost and Caulton who added triethylamine to obtain the DNIC as the sole nitrosylated (not isolated) solution species in terms of IR spectroscopy $\left(\mathrm{B}=\mathrm{NEt}_{3}\right)$ according to: ${ }^{[15]}$

$\mathrm{FeCl}_{2}+3 \mathrm{NO}+\mathrm{MeOH}+\mathrm{B} \rightarrow\left[\mathrm{FeCl}_{2}(\mathrm{NO})_{2}\right]^{-}+\mathrm{MeONO}+\mathrm{BH}^{+}$

Our attempts to reproduce this investigation led to a specification of Gwost and Caulton's statement "... when exposed to NO the solution immediately darkened; after $9 \mathrm{hr}$ of bubbling NO, the solution was deep red." In fact, the reported darkening was of a green colour which subsequently turned brownish red. Obviously, the DNIC formed in a further step after the initial formation of the corresponding MNIC.

As with the ferric variant of the standard procedure, the formation of the methyl nitrite side product was best monitored by UV-vis spectroscopy. The sequential nature of the reaction became particularly clear with fluoride as the base. (Originally, we attempted to prepare fluorido analogues of the title compounds. However, in all reactions fluoride reacted as a base, not as a coligand.) We found that the admixture of increasing amounts of fluoride to an $\mathrm{ACl} / \mathrm{FeCl}_{2} / \mathrm{MeOH}$ standard-route mixture made the green solution (at no added fluoride) turn more and more reddish brown according to the equation:

$\left[\mathrm{FeCl}_{3}(\mathrm{NO})\right]^{-}+\mathrm{F}^{-}+2 \mathrm{NO}+\mathrm{MeOH} \rightarrow\left[\mathrm{FeCl}_{2}(\mathrm{NO})_{2}\right]^{-}+\mathrm{Cl}^{-}+\mathrm{MeONO}+\mathrm{HF}$

Red-brown DNIC solutions are accessible more directly by using the fluoride of $\mathrm{A}$. For $\mathrm{A}=\mathrm{NMe}_{4}$ :

$\mathrm{FeCl}_{2}+2 \mathrm{NMe}_{4} \mathrm{~F}+3 \mathrm{NO}+\mathrm{MeOH} \rightarrow \mathrm{NMe}_{4}\left[\mathrm{FeCl}_{2}(\mathrm{NO})_{2}\right]+\mathrm{MeONO}+\mathrm{NMe}_{4}^{+} \mathrm{HF}_{2}^{-}$

Attempts to prepare solutions of pure DNIC included the variation of base amount. In fact, the threefold instead of a double molar amount resulted in a poor DNIC yield. Moreover, charging the reaction mixtures with four moles of fluoride over iron left the mixture unreactive towards nitric oxide. We interpreted this result with the assumption that the ferrous-salt-to-DNIC transformation was a two-step process, the first and second steps of which were governed by individual parameters. Thus MNIC formation appeared as fluoride-inhibited whereas DNIC formation was fluoride-promoted.

A two-stage procedure of this two-step reaction sequence thus accelerated the formation of the final product. A react-IR study was used to demonstrate this: first, ferrous chloride tetrahydrate was reacted rapidly in methanol with NO to the respective MNIC and small amounts of DNIC only. In the second step, the addition of base resulted in the immediate increase of the DNIC signals with a decrease of the MNIC peak.

Attempts to provide a facile standard procedure for the preparation of $\mathrm{A}\left[\mathrm{FeCl}_{2}(\mathrm{NO})_{2}\right]$ salts have been made for the tetramethylammonium counterion. Currently, the most recommendable procedure for the preparation of the respective DNIC starts from ferrous chloride and twice the molar amount of tetramethylammonium fluoride. Treatment with NO led to red-brown solutions. However, the crystallisation still took about a month to obtain only a $30 \%$ isolated yield.

One additional point should be made which highlights the fact that MNIC:DNIC ratios from a specific reaction do not depend only on the amount of base as the most important factor, but that there are other 
control parameters. One of them is the applied $\mathrm{Cl}$ :Fe molar ratio. Thus, to synthesise an MNIC or DNIC, the stoichiometric 3:1 or 2:1 ratio, respectively, should be applied. DNIC synthesis with chloride excess or MNIC synthesis with chloride shortage provokes the admixture of the respective 'wrong' NIC.

\section{DNIC formation via a ferric route}

Bearing the two-step formation of a DNIC in mind, a ferric variant should exist since it was already proved that the MNIC precursor is accessible from $\mathrm{Fe}^{\mathrm{III}}$. In fact, the addition of the 2.5-fold molar amount of tetramethylammonium fluoride to a solution of $\mathrm{FeCl}_{3}$ in methanol resulted in the formation of red-brown crystals of $\mathrm{NMe}_{4}\left[\mathrm{FeCl}_{2}(\mathrm{NO})_{2}\right]$ which, however, were accompanied by green crystals of the respective MNIC. Pure DNIC was obtained from a dilute batch containing $3 \mathrm{~mol}$ of fluoride per mol ferric salt according to the equation:

$$
\mathrm{FeCl}_{3}+2 \mathrm{NMe}_{4} \mathrm{~F}+4 \mathrm{NO}+2 \mathrm{MeOH} \rightarrow \mathrm{NMe}_{4}\left[\mathrm{FeCl}_{2}(\mathrm{NO})_{2}\right]+\mathrm{NMe}_{4} \mathrm{Cl}+2 \mathrm{MeONO}+2 \mathrm{HF}
$$

The surplus third mole of fluoride should have formed $\mathrm{NMe}_{4}\left(\mathrm{HF}_{2}\right)$ with half of the liberated hydrofluoric acid. Attempts to shift the reaction more to the right by adding another mole of fluoride showed the method's same limitation, as above, namely the inhibition of the overall nitrosylation. It should be noted that even a 3:1 F:Fe ratio resulted in poor yields for the ferrous route. Obviously, the well-known formation of fluoridoferrates(III) led to decreased base activity of the added fluoride.

Touching on the Gwost-Caulton procedure, triethylamine was employed as well. In fact, a DNIC solution formed but crystallisation was hampered.

\section{Solid $\mathrm{A}\left[\mathrm{FeCl}_{2}(\mathrm{NO})_{2}\right]$ salts: structures and IR spectra}

Despite the fact that the optimisation of the syntheses toward pure $\mathrm{A}\left[\mathrm{FeCl}_{2}(\mathrm{NO})_{2}\right]$ salts is needed, progress has yet been made in terms of structural data. For the current status, similar statements apply as for the MNIC counterpart. First, preparative procedures were reported decades ago. ${ }^{[17,24-25]}$ Second, the isolation of pure material, however, has never been demonstrated in terms of an unsuspicious structure analysis, preferably supported by matching magnetic data (see the $\mathrm{PPh}_{4}\left[\mathrm{FeCl}_{2}(\mathrm{NO})_{2}\right]$ case above). ${ }^{[18]}$ However, this point was resolved. Both the tetramethylammonium as well as the PPN salt of the dichloridodinitrosylferrate anion (for the somewhat lengthy preparation of the PPN salts see the Experimental Section) yielded reliable $\mathrm{X}$-ray data sets. As a result, four X-ray analyses of pure $\mathrm{A}\left[\mathrm{FeCl}_{2}(\mathrm{NO})_{2}\right]$ salts are available. Details are given in the SI; as an example, Figure 3 shows the structure of the anion of the $\mathrm{NMe}_{4}$ salt.

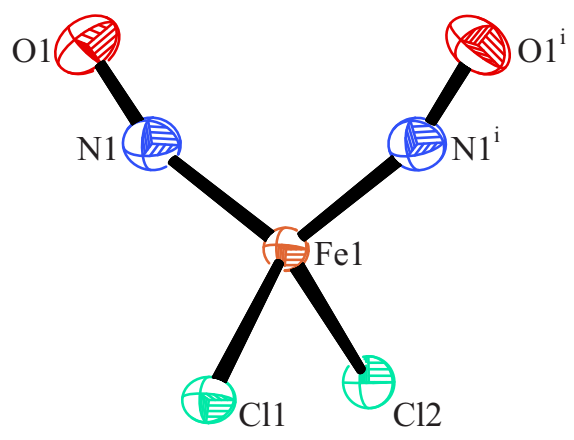

Figure 3. The structure of the anion in crystals of $\mathrm{NMe}_{4}\left[\mathrm{FeCl}_{2}(\mathrm{NO})_{2}\right](50 \%$ ellipsoids). The ion exhibits crystallographic $C_{\mathrm{s}}$ symmetry. Distances in $\AA$ : Fe1-N1 1.709(2), N1-O1 1.146(2), Fe1-Cl1 2.2797(8), Fe1-Cl2 2.2751(7). Angles (in degrees): Fe1-N1-O1 160.8(2), N1-Fe-N1 108.30(8), Cl1-Fe1-Cl2 107.41(3).

Unlike the MNIC results, all X-ray analyses revealed the same atomic distances in a narrow range 
despite the different synthetic routes that were used to prepare them. In addition, the magnetic susceptibility of the PPN salt prepared on the ferrous route $\left(\mu_{\text {eff }}=1.92\right)$, complied with the expected $S=1 / 2 \operatorname{spin}(1.73$ spin only).

The most severe problem for the $\mathrm{A}\left[\mathrm{FeCl}_{3}(\mathrm{NO})\right]$ preparation via the ferric route, the co-crystallisation with $\mathrm{A}\left[\mathrm{FeCl}_{4}\right]$, thus did not seem to be problematic here. Future work on the optimisation of the DNIC branch thus appears promising for both a ferrous and a ferric variant. Speculating on the reasons for the lack of a disadvantage for a ferric route to the DNIC, two points seem obvious. The first is a crystallographic argument and points to the lesser similarity and thus a worse mutual replaceability of the $\left[\mathrm{FeCl}_{4}\right]^{-}$and the $\left[\mathrm{FeCl}_{2}(\mathrm{NO})_{2}\right]^{-}$ion. However, the second argument appeared to be the decisive one: the reaction equation above practically runs to completeness in a shorter period of time; hence, there is no $\left[\mathrm{FeCl}_{4}\right]^{-}$to cocrystallise.

In the next chapter, the co-crystallisation of $\mathrm{A}\left[\mathrm{FeCl}_{3}(\mathrm{NO})\right]$ and $\mathrm{A}\left[\mathrm{FeCl}_{2}(\mathrm{NO})_{2}\right]$ salts will be addressed as well. In this chapter on DNIC synthesis, however, that property of MNIC/DNIC mixtures did not create a problem since it was easy to prepare a DNIC solution free of MNIC. IR spectroscopy was mentioned above for routinely monitoring MNIC vs. DNIC formation. For solid DNICs, two vibrational bands for the $\mathrm{N}-\mathrm{O}$ stretch, one for the symmetrical, one for the asymmetrical, were observed at values similar to those of the solution. For $\mathrm{NMe}_{4}\left[\mathrm{FeCl}_{2}(\mathrm{NO})_{2}\right], 1783$ and $1687 \mathrm{~cm}^{-1}$ were found.

\section{Solid $\mathrm{A}\left[\mathrm{FeX}_{2}(\mathrm{NO})_{2}\right]$-type bromido- and iodido-DNICs}

As with the respective MNICs, solutions of the bromido analogues were obtained by the same procedures. However, pure crystals of a bromido-DNIC have not yet been obtained by this route. Instead, we present the first structure determination of an $\mathrm{A}\left[\mathrm{FeBr}_{2}(\mathrm{NO})_{2}\right]$ salt as a preliminary result in respect to the synthesis of the mother liquor. Hence, red-brown crystals of PPN $\left[\mathrm{FeBr}_{2}(\mathrm{NO})_{2}\right]$ were obtained from an MNIC batch (molar ratio Fe:Br of 1:3) to which some aqueous solution of hydrobromic acid (ca. half a mole per mol iron) was added. The bromido-DNIC's formation points to a subsequent disproportionation of the primary product, the MNIC, according to the equation: $2\left[\mathrm{FeBr}_{3}(\mathrm{NO})\right]^{-} \rightarrow\left[\mathrm{FeBr}_{2}(\mathrm{NO})_{2}\right]^{-}+\left[\mathrm{FeBr}_{4}\right]^{-}$. Details of this reaction remain to be clarified as well as the significance of $\mathrm{Fe}^{\mathrm{III}}$ reduction by $\mathrm{NO}$ in the bromide regime. The structure of the anion in the bromido-DNIC is shown in Figure 4. The formation of a $\left\{\mathrm{Fe}(\mathrm{NO})_{2}\right\}^{9}$-type DNIC by the dissociation of an $\{\mathrm{FeNO}\}^{7}$-type MNIC had been reported often, most recently in Ref. ${ }^{[22]}$ (and references cited therein).

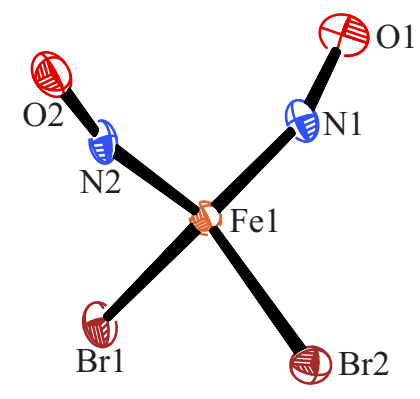

Figure 4. The structure of the anion in crystals of PPN $\left[\mathrm{FeBr}_{2}(\mathrm{NO})_{2}\right]$ (50\% ellipsoids). Distances in $\AA$ : Fe1-Br1 2.4108(4), Fe1-Br2 2.4173(4), Fe1-N1 1.707(2), Fe1-N2 1.723(2), N1-O1 1.145(2), N2-O2 1.099(3). Angles (in degrees): Fe1-N1-O1 162.73(18), Fe1-N2-O2 166.34(18), N1-Fe1-N2 112.26(9), Br1-Fe1-Br2 109.12(1).

The iodido-DNIC showed a markedly higher formation tendency. Salts with the $\left[\mathrm{FeI}_{2}(\mathrm{NO})_{2}\right]^{-}$anion were thus obtained on attempts to synthesise iodido-MNICs, the counterions being $\mathrm{AsPh}_{4}{ }^{+}, \mathrm{PPh}_{4}{ }^{+}$, and $\mathrm{PPN}^{+}$. 
As a by-product, $\mathrm{I}_{3}^{-}$was formed in all batches, partly as crystals of $\mathrm{A}^{+} \mathrm{I}_{3}^{-}$, and, in one case, co-crystallised with the DNIC. The reaction seems to have followed the equation: $\mathrm{Fe}^{2+}+3.5 \mathrm{I}^{-}+2 \mathrm{NO} \rightarrow\left[\mathrm{FeI}_{2}(\mathrm{NO})_{2}\right]^{-}+$ $0.5 \mathrm{I}^{-}$.

Crystal structures of PPN $\left[\mathrm{FeI}_{2}(\mathrm{NO})_{2}\right]$ and $(\mathrm{PPN})_{2}\left[\mathrm{FeI}_{2}(\mathrm{NO})_{2}\right]\left(\mathrm{I}_{3}\right)$ as well as $\mathrm{AsPh}_{4}\left[\mathrm{FeI}_{2}(\mathrm{NO})_{2}\right]$ and $\mathrm{PPh}_{4}\left[\mathrm{FeI}_{2}(\mathrm{NO})_{2}\right]$ were described in the SI. PPN $\left[\mathrm{FeI}_{2}(\mathrm{NO})_{2}\right]$ was isotypic with the same salt from a different synthetic route. ${ }^{[21]}$

\section{Crystallography: crystal pathology and seeding, crystal packing}

\section{Crystal pathology and seeding}

As a most characteristic feature, crystalline halogenidonitrosylferrates exhibit a typical pathology which originates because of the exchangeability of chloride and nitrosyl moieties on the point positions occupied by the ligands. Notably, this statement does not include the supposed occurrence of $\mathrm{Cl} / \mathrm{NO}$ disorder in the pure products. Instead, anions of the same charge such as $\left[\mathrm{FeCl}_{2}(\mathrm{NO})_{2}\right]^{-},\left[\mathrm{FeCl}_{3}(\mathrm{NO})\right]^{-}$, and $\left[\mathrm{FeCl}_{4}\right]^{-}$ occupy the same positions in a crystal structure, if they are present, side by side, in the respective mother liquors. From a synthetic viewpoint, chloride/nitrosyl exchangeability at a constant anion charge meant that a proven method, recrystallisation, was no longer available as a purification procedure. Instead, these anions formed solid solutions which, on the one hand, obscured the crystallographic characterisation, and, on the other, impeded the preparation of pure substances for further use in physical and chemical experiments.

The irritating observation that there was no general $\mathrm{Cl} / \mathrm{NO}$ disorder problem in the pure substances may be explained by the following observation. By using the standard route starting from $\mathrm{FeCl}_{2}$ in $\mathrm{MeOH}$, the addition of $\left(\mathrm{NEt}_{4}\right) \mathrm{Cl}$ as the cation source, followed by $\mathrm{NO}$ exposure, resulted in a green solution. In contrast to other cations, these $\mathrm{NEt}_{4}$ batches did not crystallise within prolonged periods of time (more than half a year). By using the $\mathrm{FeCl}_{3}$ variant, green solutions were obtained as well. But now, crystallisation took place in the course of about two weeks. Structure determination revealed an $\mathrm{NEt}_{4}\left[\mathrm{FeCl}_{3}(\mathrm{NO})\right]$, contaminated with about $15 \%\left[\mathrm{FeCl}_{4}\right]^{-}$content. From this observation we conclude that the contaminant $\mathrm{NEt}_{4}\left[\mathrm{FeCl}_{4}\right]$ was not homogenously distributed in the NO-containing bulk but had served as a seed due to its lower solubility and thus gave rise to the epitaxial growth of the bulk.

The presence of ferric contamination became obvious in the measurement of the magnetic properties of the samples (see the SI). Values in the expected range for an $S=3 / 2$ species were measured only for material from the standard route whereas ferric-route samples showed the same high values that had been reported in the 1958 work by Griffith et al. in their first description of products from $\mathrm{FeCl}_{3}(\mathrm{sol}) / \mathrm{NO}(\mathrm{g}) / \mathrm{EtOH}$ reactions. ${ }^{[13]}$

Samples with the $\mathrm{NMe}_{4}{ }^{+}$counterion behaved similarly and shall be used as an example which focuses on numerical aspects. The specific methodological problem that arises from samples with a small amount of ferric contaminant/seed is that, on the one hand, the figures of merit of standard X-ray analysis hardly indicate the presence of a contaminant. On the other hand, structural parameters such as atomic distances may be seriously in error. Thus, isotypic orthorhombic crystals of $\mathrm{NMe}_{4}\left[\mathrm{FeCl}_{3}(\mathrm{NO})\right]$ in the polar space group $P c a 2_{1}$ were prepared both by the standard ferrous route and by the ferric variant. Table 1 shows significant numbers in four rows: (1) the BP86/def2-TZVP result from Table 2 as a guideline for what the expected values are, (2) the result from a room-temperature measurement on crystals from the ferrous route, (3) the well-matching results from a corrected low-temperature measurement $\left(-100^{\circ} \mathrm{C}\right)$ on crystals from the ferric route, and (4) the same as 3 without a correction for ferric contaminants. 
Table 1. Atomic distances from X-ray analyses on a crystal of pure (second row) and $\mathrm{Fe}^{\mathrm{III}}$-contaminated (third and fourth row) $\mathrm{NMe}_{4}\left[\mathrm{FeCl}_{3}(\mathrm{NO})\right.$ ]; 'uncorrected' refers to a nitrosyl position fully occupied by an $\mathrm{NO}$ group; 'corrected' includes splitting of the nitrosyl position which, after refinement, was occupied by $0.912(13) \mathrm{NO}$ and $0.088 \mathrm{Cl}$ with $\mathrm{Fe}-$ $\mathrm{Cl} 2.16(3) \AA$ (compare the typical Fe ${ }^{\mathrm{III}}-\mathrm{Cl}$ distance of $2.188 \AA$ explicated in the 'Charges' chapter below).

\begin{tabular}{lllll}
\hline & $\mathrm{Fe}-\mathrm{N} / \AA$ & $\mathrm{N}-\mathrm{O} / \AA$ & $\Delta \rho / e \AA^{-3}$ & $\mathrm{wR} 2$ \\
\hline $\mathrm{BP}^{\mathrm{II}} 6^{\mathrm{b}}($ see Table 2) & 1.702 & 1.165 & & \\
$\mathrm{Fe}^{\mathrm{II}}$ route & $1.710(7)$ & $1.154(8)$ & 0.367 & 0.0875 \\
$\mathrm{Fe}^{\mathrm{III}}$ route, corrected & $1.729(7)$ & $1.145(12)$ & 0.311 & 0.0372 \\
$\mathrm{Fe}^{\text {III }}$ route, uncorrected & $1.789(3)$ & $1.059(3)$ & 0.293 & 0.0378 \\
\hline
\end{tabular}

Figure 5 shows both uncorrected (left) and corrected (right) results. Despite the fact that the usual figures of merit of the X-ray analysis such as the wR2 value or the residual electron density did not mirror the crystal's pathology of presumably containing an $\mathrm{NMe}_{4}\left[\mathrm{Fe}^{\mathrm{III}} \mathrm{Cl}_{4}\right]$ nucleus (Table 1), the thermal ellipsoids of the nitrosyl group evoke a strong suspicion that something might be wrong. In particular, the nitrogen atom should not vibrate preferably along the strong $\mathrm{N}-\mathrm{O}$ bond but perpendicular to it. Note that both the $\mathrm{N}$ and $\mathrm{O}$ ellipsoids looked reasonable after the correction the details of which are given in the table and figure captions.

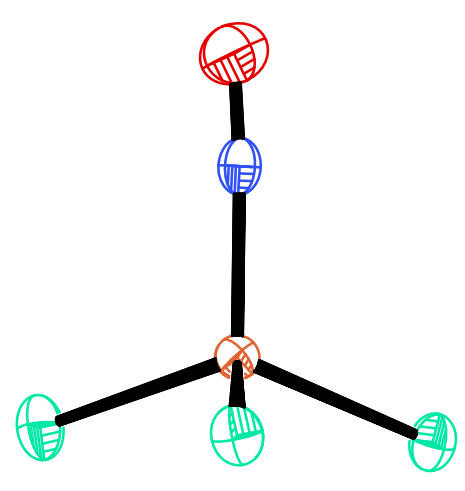

(a)

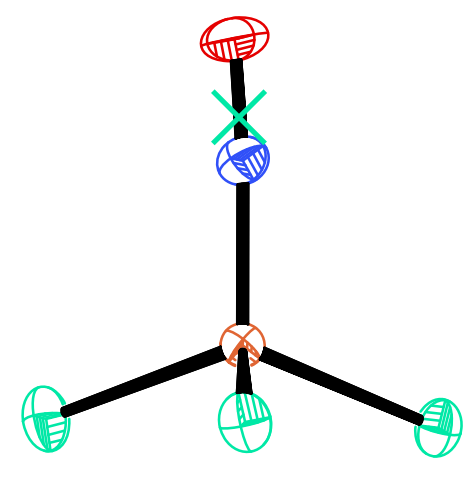

(b)

Figure 5. (a) 50\% ellipsoids from the uncorrected X-ray analysis. (b) The same after splitting of the NO position into the depicted $\mathrm{N}$ and $\mathrm{O}$ atoms (site occupancy 0.912 ) and 0.088 isotropically refined $\mathrm{Cl}$ close to the $\mathrm{N}$ atom (green cross).

PPN $\left[\mathrm{FeCl}_{3}(\mathrm{NO})\right]$ was chosen to decide whether (1) ferrate(III) seeding mirrors an unavoidable ferric content of a mother liquor of the ferric route, i.e., a thermodynamic limitation of the route, or (2) the reaction may run practically to completeness but rapid ferrate(III) seeding interferes with the redox reaction which marks a kinetic problem. To differentiate these cases, it helps to reformulate the equation above as:

$$
\mathrm{A}^{+} \mathrm{Cl}^{-}+\mathrm{FeCl}_{3}+2 \mathrm{NO} \rightleftarrows \mathrm{A}\left[\mathrm{FeCl}_{4}\right]+2 \mathrm{NO} \rightleftarrows \mathrm{A}^{+}\left[\mathrm{FeCl}_{3}(\mathrm{NO})\right]^{-}+\mathrm{MeONO}+\mathrm{HCl}
$$

In fact, the formation of a yellowish precipitate on addition of $\mathrm{ACl}$ and $\mathrm{FeCl}_{3}$ was frequently observed. In these batches, $\mathrm{A}\left[\mathrm{FeCl}_{4}\right]$ seeds were present from the beginning of nitrosylation.

In case 1, the thermodynamic limitation implied that either the first or the second equilibrium, or both, may leave substantial amounts of the respective components of the left sides unreacted in solution. Case 2 implied that, due to their lower solubility, seeds of $\mathrm{A}\left[\mathrm{FeCl}_{4}\right]$ formed and remained, partly or completely, in the solid state where their accessibility was insufficient to re-enter the equilibrium. This view is supported by the consideration that the attempted product forms a shell about these seeds.

To decide between these cases, the precipitation of $\mathrm{A}\left[\mathrm{FeCl}_{4}\right]$ was prohibited by the dilution of the reaction mixture to such an extent that turbidity was not observed for prolonged periods of reaction time. As 
a result, pure, 'ferrous-route-quality' crystals of $\mathrm{PPN}\left[\mathrm{FeCl}_{3}(\mathrm{NO})\right]$ were obtained from a ferric chloride solution with a tenfold solvent content. As the most meaningful method, the magnetic characterisation revealed the following effective Bohr magneton numbers $\left(\mu_{\text {eff }}\right)$ for $\mathrm{PPN}\left[\mathrm{FeCl}_{3}(\mathrm{NO})\right]$ from the ferrous route: 4.20, from the standard ferric route: 5.29, from the diluted ferric batch: 4.20 (compare the spin-only value for $\left.S=3 / 2: \mu_{\text {eff }}=3.87\right)$.

\section{Crystal packing}

The crystal structures showed common features. Most important for our goal of rotating the nitrosyl ligand on irradiation was the conspicuous lack of tight interatomic contacts that included the NO groups which, thus, were not spatially fixed in a narrow cavity. Instead, (non-classical) hydrogen bonds, as the most typical interatomic interaction, ran solely from the respective hydrogen-bond donors to halogenido acceptors.

This behaviour mirrored the electrostatic situation of the anions. Figure 6 shows the electrostatic potential (ESP) of the $\left[\mathrm{FeCl}_{3}(\mathrm{NO})\right]^{-}$ion mapped on the ion's van-der-Waals surface (following common usage, the 0.001 a.u. surface was taken as the van der Waals shape; p. 461 in Ref. ${ }^{[26]}$.

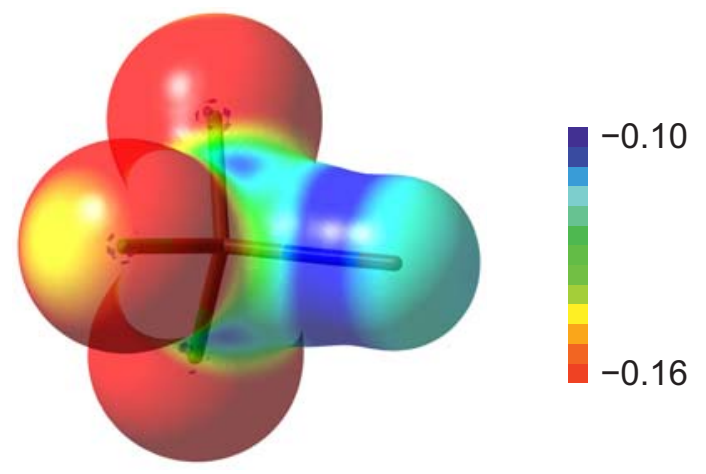

Figure 6. The electrostatic potential (ESP) of the $\left[\mathrm{FeCl}_{3}(\mathrm{NO})\right]^{-}$ion $(\mathrm{Cl}$ left and backwards, NO right; atomic units), mapped on the 0.001 a.u. (ca. $0.0067 \mathrm{e} \AA^{-3}$ ) surface of the total electron density. The values were taken from a BP86/def2-TZVP calculation on the free $\left[\mathrm{FeCl}_{3}(\mathrm{NO})\right]^{-}$ion.

The charge distribution shows the highest negative charge on the chlorine atoms. It is not uniform over the entire shape of each individual ligand, but the polar regions in the extensions of the $\mathrm{Fe}-\mathrm{Cl}$ and the $\mathrm{Fe}-\mathrm{N}-$ O bonds differ from the lateral regions about the bonds. Thus, on the one hand, the poles of the chlorido ligands show a decreased negative charge, the typical $\sigma$ holes. ${ }^{[27]}$ On the other hand, the pole about the nitrosyl-oxygen showed an increase of negative charge with respect to the lateral region about the $\mathrm{Fe}-\mathrm{N}-\mathrm{O}$ bond due to the lone pair at the $\mathrm{O}$ atom. As an overall result, the cation-binding directions are expected to be normal to the $\mathrm{Fe}-\mathrm{Cl}$ vectors on the 'back side' of the anion opposite to the nitrosyl function. In fact, the crystal structures verified this result. Figure 7 shows the prototypical situation in the salt with the $N$-methylphenazinium counterion which complies with the lateral-only, the back-side, and the NO-exclusion features derived from the ESP. 


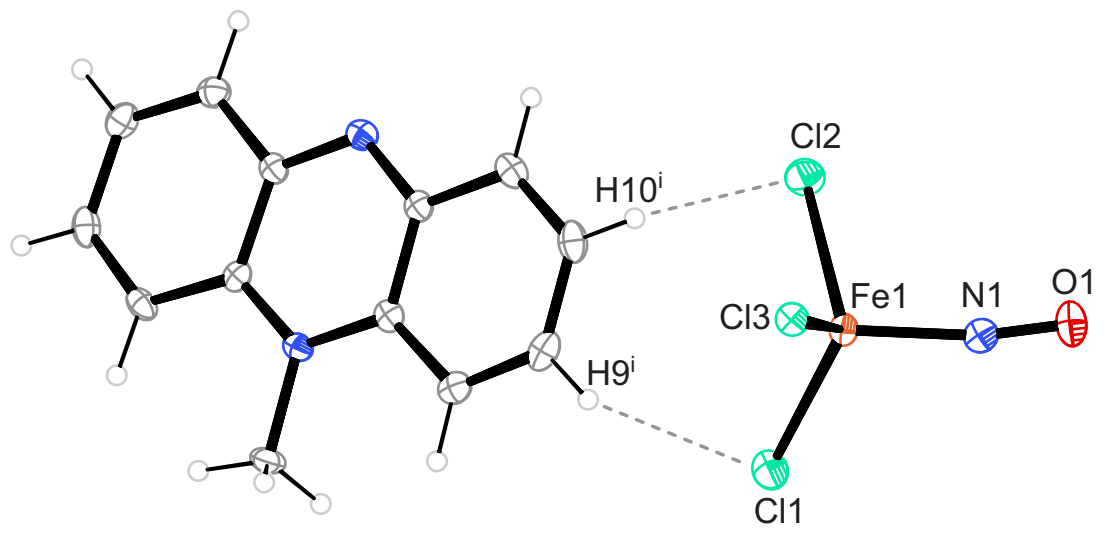

Figure 7. Mephaz ${ }^{+}\left[\mathrm{FeCl}_{3}(\mathrm{NO})\right]^{-}$. The ion pair with the shortest interatomic contact $\left(\mathrm{H} 10^{\mathrm{i} \cdots \mathrm{Cl} 2} 2.782 \AA\right.$, the second contact $\mathrm{H} 9^{\mathrm{i} \cdots \mathrm{C}} \mathrm{Cl}$ is $2.969 \AA$ ) in the anion's orientation close to Figure 6 (Ortep, $50 \%$ ellipsoid probability). Note hydrogen bonding towards the region of highest charge lateral to the $\mathrm{Fe}-\mathrm{Cl}$ bonds at the chlorine acceptor. The depicted hydrogen-bond motif is repeated with $\mathrm{Cl} 3$ and $\mathrm{Cl} 1$ as a second acceptor couple. Symmetry code: ${ }^{\mathrm{i}} 5 / 2-x, y-1 / 2,1 / 2-z$. Interatomic distances in the anion in $\AA$ : Fe1-Cl1 2.2357(7), Fe1-Cl2 2.2291(6), Fe1-Cl3 2.2594(6), Fe1-N1 1.734(2), N1-O1 1.152(2); angles (in degrees): Fe1-N1-O1 170.1(2), mean $\mathrm{Cl}-\mathrm{Fe}-\mathrm{N}$ 108.0, mean $\mathrm{Cl}-\mathrm{Fe}-\mathrm{Cl} 110.9$.

The $\mathrm{AsPh}_{4}\left[\mathrm{FeX}_{4-x}(\mathrm{NO})_{x}\right]$ structure family

Cations of the $\mathrm{EPh}_{4}{ }^{+}$type ( $\mathrm{E}$ = group-15 element) have a pronounced tendency to form square column packings, leaving inter-column channels for the anions. The various subtypes have been classified by Müller by means of a Bärnighausen tree. ${ }^{[28]}$ About half of the types belonged to the tetragonal system (14 out of 30). Only one of the tetragonal types provided an anion position without crystallographic point symmetry $\left(S_{4}\right.$ symmetry for the cation). This structure in space group $P \overline{4}$ was chosen by $\mathrm{PPh}_{4}\left[\mathrm{FeCl}_{3}(\mathrm{NO})\right]$, $\mathrm{PPh}_{4}\left[\mathrm{FeBr}_{3}(\mathrm{NO})\right]$, and $\mathrm{AsPh}_{4}\left[\mathrm{FeBr}_{3}(\mathrm{NO})\right]$. All three structures were well resolved and free of disorder. A monoclinic variant was found for $\mathrm{AsPh}_{4}\left[\mathrm{FeCl}_{3}(\mathrm{NO})\right]$ in space group $P 2_{1} / n$ with the $2_{1} / n$ symmetry parallel to the column axis. The [010] direction, which resembled the [001] direction in the tetragonal cell, was twice the tetragonal $c$ length. The square packing was slightly distorted $\left(a \approx c \approx a_{\text {tetr }} / \sqrt{2}, \beta \approx 90^{\circ}\right)$. The monoclinic variant shared a significant feature with the tetragonal cell: no crystallographic symmetry was imposed on the anion. Also the monoclinic structure was well-ordered without $\mathrm{Cl} / \mathrm{NO}$ scrambling. 


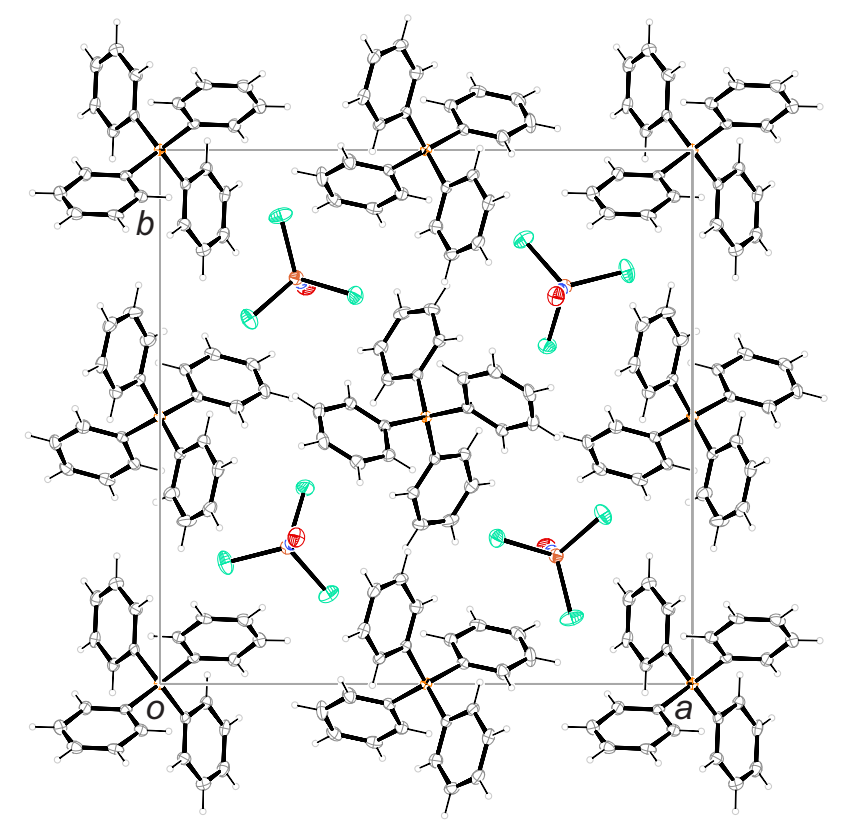

Figure 8. The crystal structure of $\mathrm{PPh}_{4}\left[\mathrm{FeCl}_{3}(\mathrm{NO})\right]$. Space group $P \overline{4}$, projection along $[00 \overline{1}]$; the $\mathrm{PPh}_{4}$ ions occupy special positions with $S_{4}$ symmetry. Ortep, $50 \%$ probability ellipsoids.

The $P \overline{4}$ cell was assigned to their brown needles by Beck to $\mathrm{AsPh}_{4}\left[\mathrm{FeCl}_{3}(\mathrm{NO})\right]$ and by Akutsu to $\mathrm{AsPh}_{4}\left[\mathrm{FeCl}_{2}(\mathrm{NO})_{2}\right] .{ }^{[18,23]}$ As has been elaborated above, both groups obviously dealt with MNIC/DNIC cocrystals (in terms of the reported room-temperature metrics of the unit cells, the Beck crystals contained a higher share of DNIC, just opposite to the claims in both papers). As a result, we can state that $\mathrm{Cl} / \mathrm{NO}$ disorder was not triggered by cation arrays which imposed crystallographic symmetry to the anion part and thus provoked disorder. The pure MNICs of this structure family crystallised free of disorder. Conversely, the pathology of the reported structures is of chemical origin. Hence, co-crystals formed from mother liquors that provided a mixture of anions which seemed to be similar enough for the mutual replacement in a crystal structure.

\section{Structure and bonding: the linear, high-spin, covalently $\pi$-bonded $\mathrm{Fe}-\mathrm{NO}$ entity}

\section{Methodology for $\left\{\mathrm{FeNO}^{7}(\mathrm{~S}=3 / 2)\right.$ species}

A detailed methodological study by Radon et al. on $\{\mathrm{FeNO}\}^{7}$ species which included both densityfunctional and wave-function methods included the $S=3 / 2$, high-spin, case using the example of the tentative 'brown ring' complex, $\left[\mathrm{Fe}\left(\mathrm{H}_{2} \mathrm{O}\right)_{5}(\mathrm{NO})\right]^{2+} \cdot{ }^{[29]}$ In the wave-function part of their study, the authors used a $\operatorname{CASSCF}(9,13)$ approach. The nine electrons placed in the active space included the lone pair at the $\mathrm{N}$ atom of a formal $\mathrm{NO}^{+}$donor ligand ( $3 \sigma$ in an $\mathrm{NO}$ molecular-orbital scheme), and the seven 'EnemarkFeltham electrons'. In total, the active space was made up of the five $\mathrm{Fe}(3 \mathrm{~d})$ orbitals, five $\mathrm{Fe}(4 \mathrm{~d})$ 'secondshell' orbitals and three NO-based orbitals: the mentioned $3 \sigma$ orbital and the two degenerate $\pi^{*}$ orbitals. This approach was also used below for the $\left[\mathrm{FeCl}_{3}(\mathrm{NO})\right]^{-}$ion.

\section{DFT investigation of the $\left[\mathrm{FeCl}_{3}(\mathrm{NO})\right]^{-}$ion}

Since a reliable assignment of the $\mathrm{N}-\mathrm{O}$ valence frequency was essential for the linkage-isomerism part of this work, the theoretical level was chosen to achieve a good agreement between experimental and calculated $v(\mathrm{~N}-\mathrm{O})$ values. As a result, popular hybrid functionals such as B3LYP or TPSSh were excluded 
since the (unscaled) $\mathrm{N}-\mathrm{O}$ frequency was calculated some $50 \mathrm{~cm}^{-1}$ too high for these functionals. A better agreement was achieved with the methods of Table 2 . Of these, the metrical parameters of the BP $86^{\mathrm{b}}$ entry were used for the wave-function-based calculations described below. For the TPSS functional, the (negligible) influence of a larger basis set (def2-aug-TZVPP instead of def2-TZVP) was checked.

Table 2. Distances, (mean) angles, and energy of the $\mathrm{N}-\mathrm{O}$ stretching vibration for six reliably analysed solids from the standard ferrous route, and the $\left[\mathrm{FeCl}_{3}(\mathrm{NO})\right]^{-}$ion in DFT calculations for the given method and the def2-TZVP basis set (Grimme's van-der-Waals correction; environment modelled by a COSMO [Orca3] or CPCM [Orca4] approach at practically infinite dielectric constant; uncorrected wave numbers tabulated). More functionals, in particular hybrid functionals, are included in Table $\mathrm{S} 1$ in the SI.

\begin{tabular}{lllllll}
\hline & $\mathrm{Fe}-\mathrm{Cl} / \AA$ & $\mathrm{Fe}-\mathrm{N} / \AA$ & $\mathrm{N}-\mathrm{O} / \AA$ & $\mathrm{Fe}-\mathrm{N}-\mathrm{O} /{ }^{\circ}$ & $\mathrm{Cl}-\mathrm{Fe}-\mathrm{Cl} /{ }^{\circ}$ & $\tilde{v}(\mathrm{~N}-\mathrm{O}) / \mathrm{cm}^{-1}$ \\
\hline mean 6×Xray & $2.236 \pm 0.006^{\mathrm{a}}$ & 1.726 & 1.149 & 173.5 & $110.1 \pm 1.2^{\mathrm{a}}$ & 1797 \\
\hline BP86 & 2.249 & 1.705 & 1.167 & 177.5 & 108.7 & 1786 \\
BP86 $^{\mathrm{b}}$ & 2.248 & 1.702 & 1.165 & 179.9 & 108.7 & 1791 \\
TPSS $^{\mathrm{c}}$ & 2.251 & 1.712 & 1.163 & 176.9 & 109.2 & 1792 \\
B97-D $_{\text {B97-D }}+20 r a$ & 2.268 & 1.745 & 1.161 & 178.3 & 109.4 & 1799 \\
\hline
\end{tabular}

a the given standard deviation of the mean exceeds the 10-fold of the mean standard deviation of the X-ray refinement, taken as indicating a 'soft' variable in a crystalline environment

b Orca4 with $\mathrm{CPCM}$ (water) instead of Orca3.03 with $\mathrm{COSMO(water)}$

c the same values were obtained with the def2-aug-TZVPP basis set except $1790 \mathrm{~cm}^{-1}$ for the valence vibration

\section{Fractional-occupation-number-weighted density}

The analysis of the fractional-occupation-number-weighted density (FOD) as recently introduced by Grimme was used as a bridge to a wave-function-based approach to the electronic situation of the $\left[\mathrm{FeCl}_{3}(\mathrm{NO})\right]^{-}$ion. ${ }^{[30]}$ Figure 9 shows the result for one of the procedures recommended in Ref. ${ }^{[30]}$. (The result was the same for other recommended combinations of method and Fermi temperature such as TPSS at $5000 \mathrm{~K}$.) The FOD analysis indicated the orbitals that needed a correlated treatment, namely the Fe(d) and the $\mathrm{NO}\left(\pi^{*}\right)$ orbitals. In terms of the FOD, an active space of 7 electrons in 7 orbitals thus appeared as a minimum requirement for capturing electronic correlation.

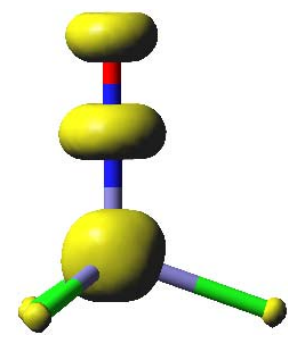

Figure 9. FOD (BHLYP/def2-TZVP, smear temperature $15000 \mathrm{~K}$, isovalue 0.005 a.u.) of the $\left[\mathrm{FeCl}_{3}(\mathrm{NO})\right]^{-}$ion.

\section{A CASSCF approach to the $\left[\mathrm{FeCl}_{3}(\mathrm{NO})\right]^{-}$ion}

For a wave-function-based approach to the bonding in $\left[\mathrm{FeCl}_{3}(\mathrm{NO})\right]^{-}$, we followed the active-space construction of Radoń's study. ${ }^{[29]}$ Thus, Figure 10 shows an active space of 9 electrons in 13 orbitals. The active space thus was chosen to exceed the minimum space of the FOD analysis by one doubly occupied MO (MO 42, the bonding counterpart of the $\sigma$-antibonding MO 48), and, as recommended for an electron-rich 3d element, a second, $4 \mathrm{~d}$ shell for the iron atom. ${ }^{[31]}$ In fact, in the ground-state study of this section, the occupation of MO 42 with 1.99 electrons in the $(9,13)$ approach revealed this MO close to inactive. Since, however, the occupation of MO 42 close to two did not encounter convergence problems in the CASSCF 
routines, we proceeded with the larger active space for the sake of comparability with the earlier study and the investigation of excited states below, which benefitted from balancing the Fe-NO antibonding MO 48 with its bonding counterpart MO 42 (Figure 10).

The most typical feature which shares the $\left[\mathrm{FeCl}_{3}(\mathrm{NO})\right]^{-}$ion with other nitrosyls, is the marked population of the $\mathrm{Fe}-\mathrm{NO} \pi^{*}$ antibonds and the corresponding depopulation of the $\mathrm{Fe}-\mathrm{NO} \pi$ bonds (compare the $0.27: 1.73$ antibond:bond population of this ion with a $0.28: 1.71$ ratio of the tentative brown-ring aqua species in Ref. ${ }^{35}$, or the $0.21: 1.79$ ratio within the natural orbital population of the related singlet species $\left[\mathrm{Fe}(\mathrm{CO})_{3}(\mathrm{NO})\right]^{-}$in Ref. ${ }^{[32]}$.) Accordingly, the leading 22211100 configuration (second shell omitted) depicted in Figure 10 contributed only about two thirds to the ground state, leaving one third to single and double excitations from the Fe-NO bonds to the antibonds.

Taken together, these numbers reveal marked static correlation as is characteristic for bonds with hindered overlap, including the textbook example of a dissociating covalent bond (p. 526 in Ref. ${ }^{[26]}$ ).

The reasons for the hindered overlap in $\left[\mathrm{FeCl}_{3}(\mathrm{NO})\right]^{-}$are twofold. The first reason applies to every nitrosyl compound derived from a (formal) $\mathrm{NO}^{+}$core. The argument may be developed starting from an arbitrary assignment of the two electron pairs involved. Let us, again arbitrarily, start from an $\mathrm{NO}^{+}$ion and a $d^{7}-\mathrm{Fe}^{\mathrm{I}}$ species with an electron pair each in $\mathrm{d}(\mathrm{xz})$ and $\mathrm{d}(\mathrm{yz})$. Now, two $\mathrm{Fe}-\mathrm{NO} \pi$ bonds are formed through the interaction of the $\mathrm{Fe}-\mathrm{d}(\mathrm{xz} / \mathrm{yz})$ pairs and the two empty $\mathrm{N}-\mathrm{O} \pi^{*}$ orbitals. The crucial point is the need for the overlap of filled (metal d) orbitals with the empty $\mathrm{N}-\mathrm{O}$ antibonds since the latter reside in the same spatial region as their occupied $\mathrm{N}-\mathrm{O}$-bonding $\pi$ counterparts. Thus, when occupied-metal-d/empty- $\pi *$ overlap occurs, at the same time, occupied-metal-d/occupied- $\mathrm{NO}(\pi)$ Pauli repulsion encumbers the metalligand interaction. (The same arguments explain the disability of two NO radicals to establish a normal N-N bond in an $\mathrm{N}_{2} \mathrm{O}_{2} \cdot{ }^{[33]}$ ) To avoid confusion in view of the various ' $\pi$ 's, the notation for a specific interaction used throughout this work is explicated in the example of MOs 44 and 45 in Figure 10, where the Fe- $\mathrm{N}$ interaction is $\pi$-bonding, and the $\mathrm{N}-\mathrm{O}$ interaction is $\pi$-antibonding, i.e., $\pi^{*}$. The specific interaction addressed is indicated by a '-'. Hence, formulations such as 'Fe-NO $\pi$ bond', 'N-O $\pi$ * interaction', and 'N$\mathrm{O} \pi$ bond' define the interaction in question.

The second reason is more specific, but is caused by operative Pauli repulsion as well. In a high-spin, $S=3 / 2,\left\{\mathrm{FeNO}^{7}\right.$ species, the nitrogen atom's lone pair faces the singly occupied $\mathrm{d}\left(\mathrm{z}^{2}\right)$ orbital, giving rise to a bonding (MO 42) and an antibonding interaction (MO 48). To minimise the repulsion through MO 48, many high-spin $\{\mathrm{FeNO}\}^{7}$ centres are found bent with the $\mathrm{Fe}-\mathrm{N}-\mathrm{O}$ angle ranging between about 150 and $180^{\circ}$ in a shallow potential. ${ }^{[6,34]}$ (In terms of orbital contributions, the bending resembles a $\mathrm{d}(\mathrm{xz})$ admixture to $\mathrm{d}\left(\mathrm{z}^{2}\right)$, see below in the PLI section.) However, a marked bending is missing in $\left[\mathrm{FeCl}_{3}(\mathrm{NO})\right]^{-}$, both experimentally and in the calculations. A closer inspection of the MOs in Figure 10 reveals the reason for the linearity of the FeNO moiety. Since a trans-to-NO ligand is missing in a tetrahedral species, the Fe-3d $\left(\mathrm{z}^{2}\right)$ orbital may be altered by an Fe-4p(z) admixture instead of a bending Fe-d(xz) contribution, which results in the differently sized upper and lower lobes of $\mathrm{d}\left(\mathrm{z}^{2}\right)$ indicating the destructive and constructive admixture, respectively. As a result, the antibonding character is decreased, even in the absence of bending. However, due to the option of $\mathrm{d}(\mathrm{xz})$ admixture, the bending potential is also shallow for the $\left[\mathrm{FeCl}_{3}(\mathrm{NO})\right]^{-}$ion (see Figure 16, the red circles between abscissa values of 150 and $180^{\circ}$ ).

\section{Spin}

The high-spin character of the $\left[\mathrm{FeCl}_{3}(\mathrm{NO})\right]^{-}$ion is largely caused by the singly occupied MOs $46-48$. 
There is, however, to some extent, spin polarisation along the Fe-NO fragment, as has been investigated in detail in Radon's study. ${ }^{[29]}$ In this reference, the related $\left[\mathrm{Fe}\left(\mathrm{H}_{2} \mathrm{O}\right)_{5}(\mathrm{NO})\right]^{2+}$ species exhibits, on the $\operatorname{CASSCF}(9,13)$ level, a Mulliken spin density of -0.49 on the NO ligand and 3.45 on the Fe atom. The values for $\left[\mathrm{FeCl}_{3}(\mathrm{NO})\right]^{-}$are similar: -0.50 for $\mathrm{NO}$ and 3.40 for the $\mathrm{Fe}$ atom.

Also in agreement with Ref. ${ }^{[29]}$ is the markedly functional-dependent extent of spin polarisation in DFT calculations. Thus, compare the BP86/def2-TZVP Mulliken spin densities (the aqua complex's values from Ref. ${ }^{[29]}$ in parentheses) of $\mathrm{NO}-0.50(-0.71)$ and $\mathrm{Fe} 3.40$ (3.50) with the respective B3LYP numbers: $\mathrm{NO}-1.07$ (-0.93) and Fe 3.60 (3.76). A broken-symmetry approach offers an alternative perspective on the antiferromagnetic character of the Fe-NO interaction. As a result, the considerable overlap of the $\alpha$ and $\beta$ part of the Fe-NO $\pi$ bonds in terms of a corresponding-orbital transformation resulted in $S=0.84$ on the TPSSh/def2-TZVP level; a value that shows close resemblance to a bonding analysis on related DNICs. ${ }^{[35]}$ In both MNICs and DNICs, the typically large values of $S$ close to 1 indicate the largely covalent character of the $\mathrm{Fe}-\mathrm{NO}$ interaction. ${ }^{[36]}$

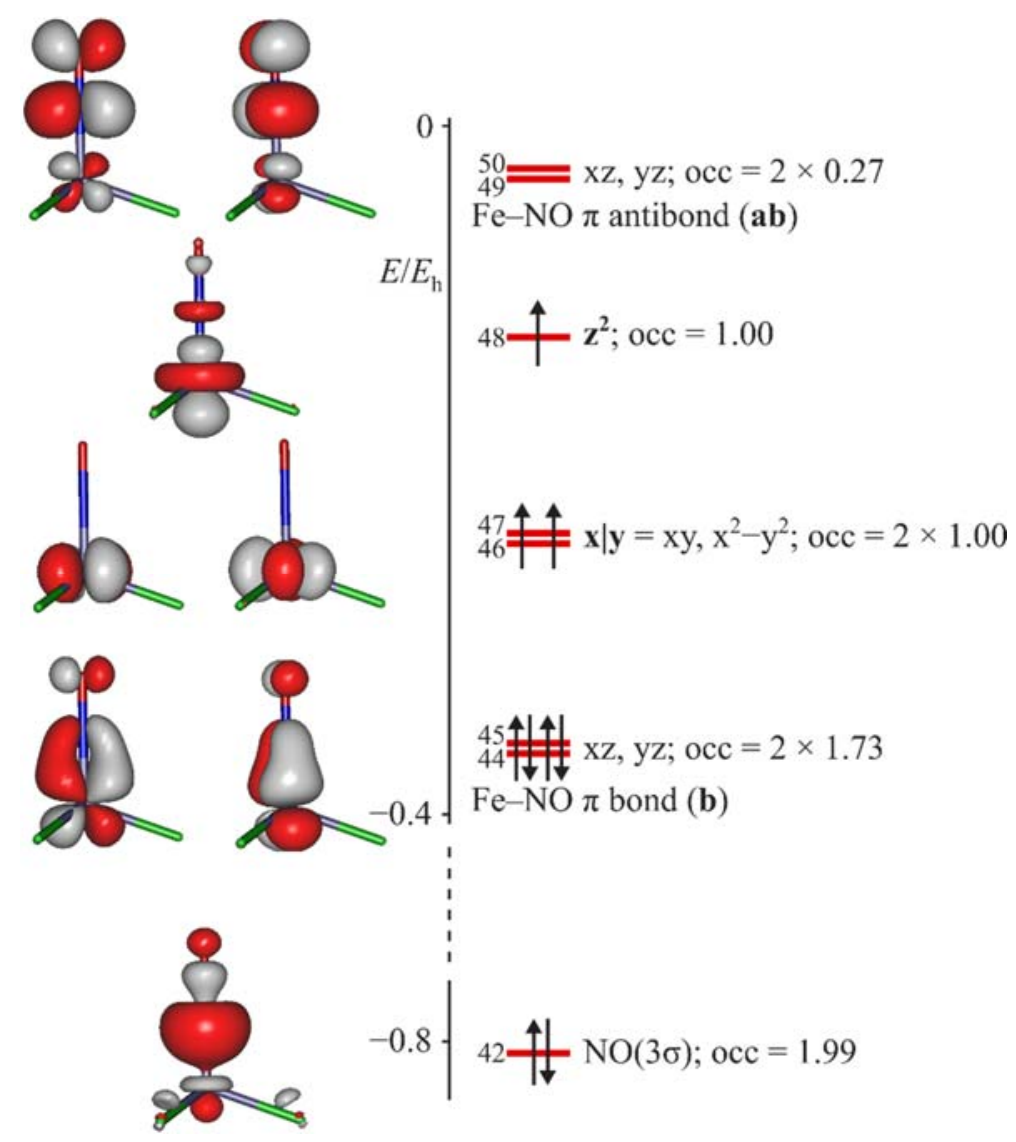

Figure 10. Frontier orbitals of the $\left[\mathrm{FeCl}_{3}(\mathrm{NO})\right]^{-}$ion $[\operatorname{CASSCF}(9,13) /$ def2-TZVP; isovalue 0.06 a.u.]. Orbital labels refer to Cartesian axes: $z$ up, $y$ to the right, $x$ to the viewer; orbital numbering starts with "1" (= Orca numbering +1$)$. The 22211100 occupation pattern indicated by the arrows refers to the ground state's leading configuration (65\% contribution). Bold: the abbreviation of a level used in Table 6.

\section{Charges}

The bonding description of the Fe-NO moiety derived so far focuses on two $\mathrm{Fe}-\mathrm{NO} \pi$ bonds formed by the $\mathrm{Fe}-\mathrm{d}(\mathrm{xz})$ and $\mathrm{Fe}-\mathrm{d}(\mathrm{yz}) \mathrm{AOs}$ on the one hand and the $\mathrm{N}-\mathrm{O}-\pi^{*}(\mathrm{x})$ and $\mathrm{N}-\mathrm{O}-\pi^{*}(\mathrm{y})$ MOs on the other. If the four electrons involved in these two bonds are shared equally between the metal and the ligand, i.e., if a purely covalent interaction is assumed, the nitrosyl ligand with the then doubly occupied $\pi^{*}$ MOs would 
count as $\mathrm{NO}^{-}$, leaving the iron centre as $\mathrm{Fe}^{\mathrm{III}}$. Starting, notionally, from $\mathrm{Fe}^{\mathrm{I}}$ and $\mathrm{NO}^{+}$(as has been done in the CASSCF section), purely covalent $\pi$ (back)bonds would be obtained by completely delocalising the $\mathrm{d}(\mathrm{xz}) / \mathrm{d}(\mathrm{yz})$ pairs into the $\mathrm{Fe}-\mathrm{NO}$ bonds.

The first hint that the assumption of backbonding towards perfect covalence is too far-reaching, comes from the mere inspection of the MOs in Figure 10. In a purely covalent bond, the contributions of the bonding partners to both the bond and the antibond would be equal. Figure 10, however, shows a higher contribution of the metal $\mathrm{d}$ orbital to the bond and a lower one to the antibond. Hence, we should not end up with the charge -1 for the nitrosyl ligand but with a smaller absolute value.

A second hint may be derived from structural data. Well-resolved X-ray data of tetrachloridoferrates are available for both the oxidation states II and III. For Fe ${ }^{\text {II }}$, the CCDC provides data sets for tetrachloridoferrates(II) (BERROF01, FIWGIB, GOXLUA, IFEGUY, TMAFEC), as well as for tetrachloridoferrates(III) (FUGDER, KURPET, QUXFAR, MECXUO, SURRON). For the ferrates(II), the mean Fe-Cl distance of the cited entries is $2.317 \AA$, whereas $2.188 \AA$ is the mean of the $\mathrm{Fe}^{\mathrm{III}}-\mathrm{Cl}$ distances. Due to the somewhat covalent character of the $\mathrm{Fe}-\mathrm{Cl}$ bonds, the difference among these values $(0.129 \AA)$ is slightly smaller than the difference between Shannon's ionic radii that were derived from fluorides and oxides $(0.135 \AA$ for hexacoordinate high-spin $\mathrm{Fe}^{\mathrm{II} / \mathrm{III}}, 0.14 \AA$ for tetracoordinate $\left.\mathrm{Fe}^{\mathrm{II} / \mathrm{III}}\right) .{ }^{[37]}$ Keeping these fixed points in mind, the mean $\mathrm{Fe}-\mathrm{Cl}$ distance from $\mathrm{X}$-ray data on the $\left[\mathrm{FeCl}_{3}(\mathrm{NO})\right]^{-}$ion from Table 2 of $2.236 \AA$ points at the oxidation state of the iron central atom between II and III, say $2.5+x$, which, in turn, assigns a charge of $-0.5+x$ to the nitrosyl ligand. To this end, we see a, more or less, covalent nitrosyl-iron interaction through two $\pi$ bonds which are polarised towards the metal.

Table 3. Population analyses. The first three entries refer to Mulliken charges for the respective method (def2-TZVP basis for all calculations). The bottom entry shows charges from a QTAIM analysis based on the BP86 calculation of the second entry.

\begin{tabular}{lllll}
\hline & $\mathrm{Fe}$ & $\mathrm{N}$ & $\mathrm{O}$ & $\mathrm{Cl}$ \\
\hline Mulliken charge: & & & & \\
CASSCF & 1.05 & 0.25 & -0.26 & -0.68 \\
BP86 & 0.47 & 0.11 & -0.10 & -0.50 \\
TPSSh & 0.57 & 0.15 & -0.12 & -0.54 \\
\hline QTAIM (BP86) & 1.26 & 0.08 & -0.36 & -0.66 \\
\hline
\end{tabular}

Finally, population analyses may contribute to this issue (Table 3). For the chlorido ligands, the values span a rather narrow range distinctly below a full negative charge. Thus, the $\mathrm{Fe}-\mathrm{Cl}$ bonds appear to be ionic with a markedly covalent share. For the nitrosyl ligand, Mulliken charges for $\mathrm{N}$ and $\mathrm{O}$ sum up to values close to zero, regardless of whether wave-function or DFT methods were employed.

A QTAIM analysis resulted in a slightly more positive central atom and a slightly more negatively charged nitrosyl ligand. Taken together, the approximately $-0.5+x$ charge derived from the 'chlorido probe' above appears to be reliable for $x$ values up to one half.

\section{DFT and WFT investigation of the $\left[\mathrm{FeCl}_{2}(\mathrm{NO})_{2}\right]^{-}$ion}

Most of the computational steps reported above were also performed for the DNIC analogue, the $\left[\mathrm{FeCl}_{2}(\mathrm{NO})_{2}\right]^{-}$ion. Significant details include the match of the metric and vibrational parameters (Table 4) and the FOD density which resembles the result for the MNIC.

Table 4. Distances, (mean) angles, and energy of the N-O stretching vibration for four reliably analysed solids and the $\left[\mathrm{FeCl}_{2}(\mathrm{NO})_{2}\right]^{-}$ion in DFT calculations for the method $\mathrm{BP}^{\mathrm{b}} 6^{\mathrm{b}}$ of Table 2 . The subscript ' $\mathrm{fCl}$ ' denotes a geometry 
optimisation with the $\mathrm{Fe}-\mathrm{Cl}$ distance fixed to the mean experimental value.

\begin{tabular}{lllllll}
\hline & $\mathrm{Fe}-\mathrm{Cl} / \AA$ & $\mathrm{Fe}-\mathrm{N} / \AA$ & $\mathrm{N}-\mathrm{O} / \AA$ & $\mathrm{Fe}-\mathrm{N}-\mathrm{O} /{ }^{\circ}$ & $\mathrm{N}-\mathrm{Fe}-\mathrm{N} /{ }^{\circ}$ & $\tilde{v}(\mathrm{~N}-\mathrm{O}) / \mathrm{cm}^{-1}$ \\
\hline mean $4 \times \mathrm{Xray}$ & 2.275 & 1.702 & 1.158 & 162.6 & 109.5 & 1694,1778 \\
BP86 $^{\mathrm{b}}$ & 2.229 & 1.665 & 1.178 & 161.8 & 110.3 & 1678,1766 \\
$\mathrm{BP}_{6 \mathrm{fCl}}$ & $2.275(\mathrm{f})$ & 1.666 & 1.179 & 161.7 & 110.0 & 1677,1765 \\
\hline
\end{tabular}

For the wave-function approach, the lone pairs at the nitrogen atoms were not included in the active space this time (but see the calculation of excited states below). Hence, it was made up of the five Fe-d orbitals, two pairs of NO- $\pi^{*}$ levels, and a second shell for Fe (14 orbitals in sum). The active space contains the 9 'Enemark-Feltham' electron. Within this space, a $\operatorname{CASSCF}(9,14)$ calculation showed the close relationship between the DNIC and the respective MNIC.

The bonding situation is depicted in Figure 11. The orbital occupation numbers resemble the MNIC (0.27:1.73) with respect to the antibond:bond population (0.26:1.74). At about one half, the weight of the leading configuration 222210000 is still smaller compared to the two thirds for the MNIC, leaving the other half for bond-to-antibond excitations.

Mulliken spin densities depended on the method: CASSCF yielded 1.60 for Fe, -0.31 for NO, and a vanishing spin density of 0.01 for $\mathrm{Cl}$. The respective BP86 values were 1.60 for $\mathrm{Fe},-0.39$ for NO, 0.09 for Cl. Mulliken charges showed a larger method-dependence (Table 5).

Table 5. Population analyses. The first three entries refer to Mulliken charges for the respective method (def2-TZVP basis for all calculations). The bottom entry shows charges from a QTAIM analysis based on the BP86 calculation of the second entry.

\begin{tabular}{lllll}
\hline & $\mathrm{Fe}$ & $\mathrm{N}$ & $\mathrm{O}$ & $\mathrm{Cl}$ \\
\hline Mulliken charge: & & & & \\
CASSCF & 0.96 & 0.08 & -0.35 & -0.71 \\
BP86 & 0.38 & 0.02 & -0.16 & -0.55 \\
TPSSh & 0.44 & 0.05 & -0.19 & -0.59 \\
\hline QTAIM (BP86) & 1.16 & 0.32 & -0.41 & -0.71 \\
\hline
\end{tabular}

With these values, the $\alpha$ spin excess on the iron atom is almost the same for the MNIC and the DNIC species, leaving about half the $\beta$ spin excess for the DNIC's individual nitrosyl ligand compared to the MNIC. 

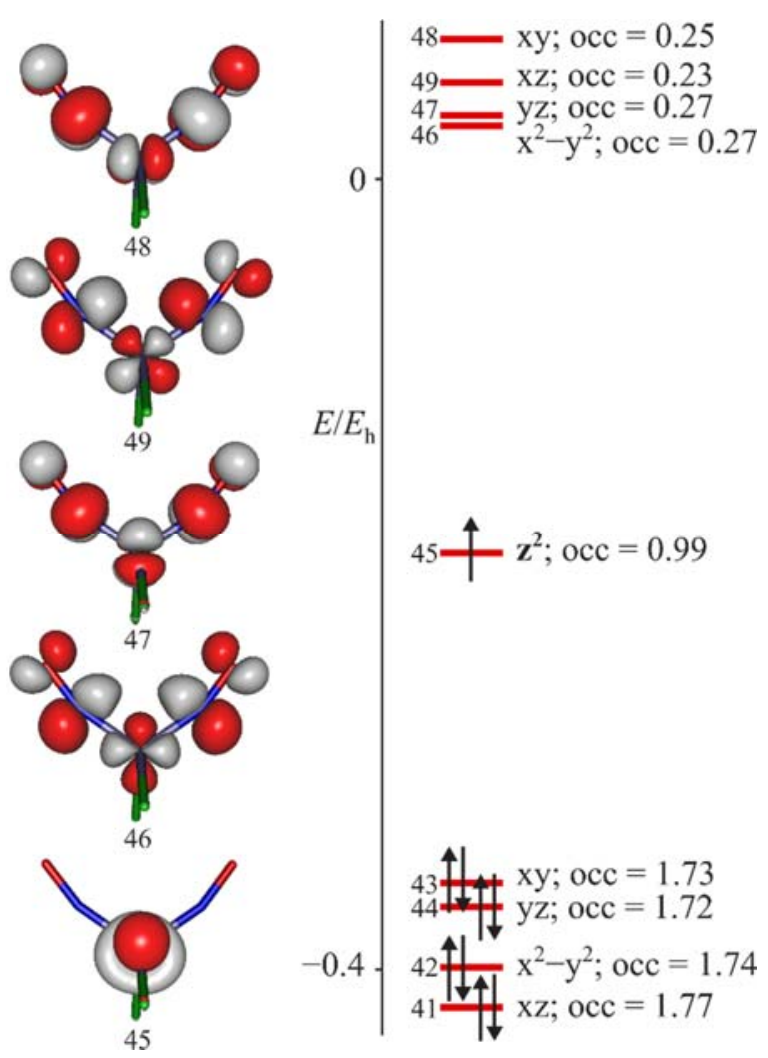

Figure 11. Frontier orbitals of the $\left[\mathrm{FeCl}_{2}(\mathrm{NO})_{2}\right]^{-}$ion $[\mathrm{CASSCF}(9,14) / \mathrm{def} 2-\mathrm{TZVP}$; isovalue 0.06 a.u.]. Orbital labels refer to Cartesian axes: $z$ to the viewer, $y$ up, $x$ to the right, with a small tilt in favour of a better visualisation; orbital numbering starts with "1" (= Orca numbering + 1). The 222210000 occupation pattern indicated by the arrows refers to the ground state's leading configuration ( $52 \%$ contribution). The metal contribution is used to specify an MO. The antibonding MOs are shown which highlight, due to their additional node, the contributing AOs. The bonding MOs ensue correspondingly.

\section{Physics: the search for photo-induced linkage isomers}

$\left\{\mathrm{FeNO}^{7}(\mathrm{~S}=3 / 2)\right.$-type MNICs: $\mathrm{A}\left[\mathrm{FeCl}_{3}(\mathrm{NO})\right]$ salts

\section{UV-vis spectroscopy of the $\left[\mathrm{FeCl}_{3}(\mathrm{NO})\right]^{-}$chromophore}

The analysis of the UV-vis spectrum was a prerequisite for the photophysical investigation. Moreover, the electronic spectrum of the $\left[\mathrm{FeCl}_{3}(\mathrm{NO})\right]^{-}$chromophore should provide, in general, a deeper insight into the electronic structure of a quartet- $\{\mathrm{FeNO}\}^{7}$-type compound for two reasons. First, no absorptions of chromogenic co-ligands cover even parts of the spectrum. In terms of oxidation-state boundaries (see above), neither the colourless $\left[\mathrm{Fe}^{\mathrm{II}} \mathrm{Cl}_{4}\right]^{2-}$ nor the slightly yellow $\left[\mathrm{Fe}^{\mathrm{III}} \mathrm{Cl}_{4}\right]^{-}$ions - these two species serving as an aid to estimate the contribution of the chlorido part of the title ion - show stronger absorptions in the visible range. Second, composed of only six atoms, the $\left[\mathrm{FeCl}_{3}(\mathrm{NO})\right]^{-}$ion permits the computational analysis of excited configurations with both DFT and WFT methods.

Experimental data were available for a Kohlschütter-type solution in concentrated hydrochloric acid, for solutions in various organic solvents, and for solid samples with various counterions. Figure 12 shows a typical solution spectrum, namely that of the tetraphenylphosphonium salt in acetone. Figure 13 shows the Kubelka-Munk-transformed spectrum of the tetraethylammonium salt as a $\mathrm{BaSO}_{4}$-diluted powdered sample.

The coincidence of both spectra was satisfactory. In the solid-state spectrum, a small contribution at $16507 \mathrm{~cm}^{-1}$ was missing in the solution spectrum, and the region labelled " $\mathrm{C}$ " comprised a single Gauss 
curve in the solution spectrum but two curves in the solid.

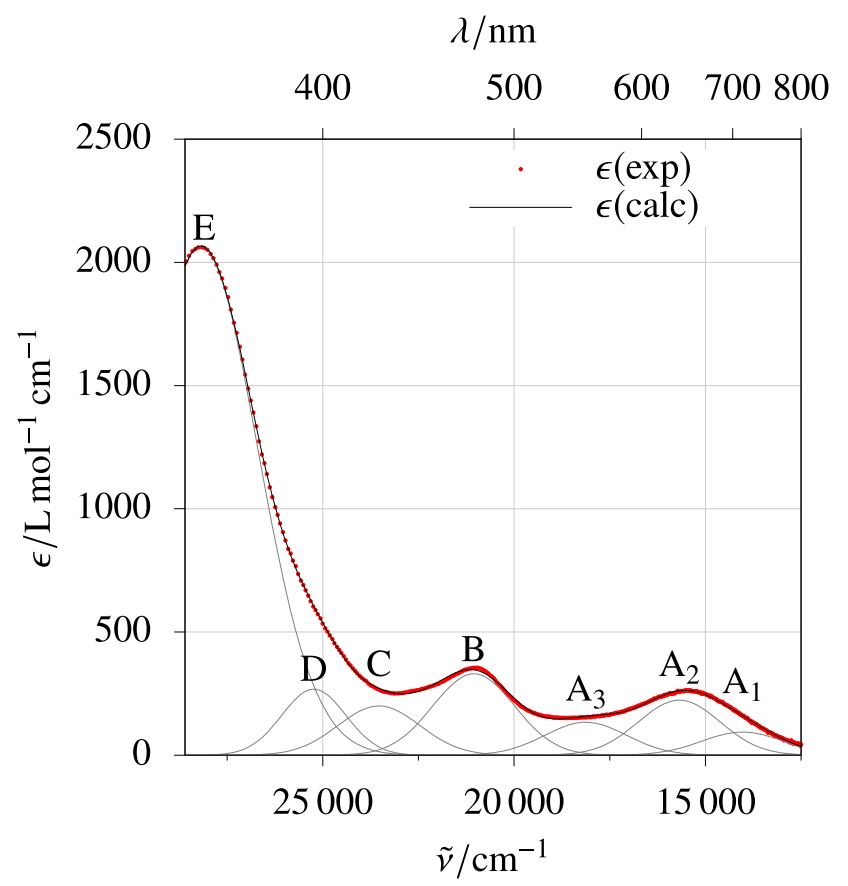

Figure 12. Gauss-deconvolved UV-vis spectrum of $\mathrm{PPh}_{4}\left[\mathrm{FeCl}_{3}(\mathrm{NO})\right]$ in acetone. Note that the sum (thin black line) of the individual Gauss curves (thin grey bell-shaped curves) coincides with the experimental points; $\varepsilon(\tilde{v})$ was fitted by seven Gauss functions; positions of the maxima in $\mathrm{cm}^{-1}: 14030,15683,18125,21054,23531$, $25233,28183$.

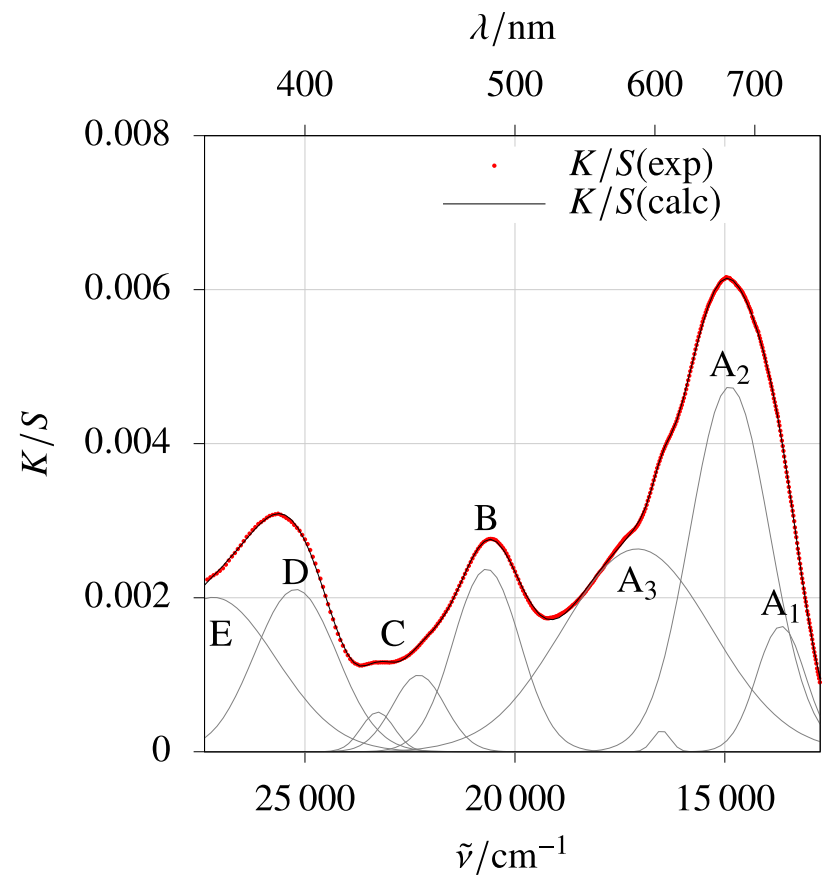

Figure 13. Gauss-deconvolved reflectance spectrum of solid $\mathrm{NEt}_{4}\left[\mathrm{FeCl}_{3}(\mathrm{NO})\right]$, diluted with $\mathrm{BaSO}_{4}$. Note that the sum (thin black line) of the individual Gauss curves (thin grey bell-shaped curves) coincides with the experimental points. $K / S(\tilde{v})$ was fitted by nine Gauss functions; positions of the maxima in $\mathrm{cm}^{-1}: 13663,14884$, 16507, 17087, 20674, 22288, 23266, 25220, 27185. 
Computational analysis of the MNIC UV-vis spectra

The absorption bands $\mathrm{A}$ and $\mathrm{B}$ of the visible region are typical for high-spin- $\{\mathrm{FeNO}\}^{7}$ chromophores in general, be it in an aqueous environment such as the 'brown-ring' complex or in an ionic liquid. ${ }^{[8 b, 38]}$ Though the spectral features of the brown or green solutions are long known, an assignment of the absorption bands has remained ambiguous. In fact, attempts to assign the bands solely by means of TD-DFT calculations remained unsatisfactory due to the functional-dependence of the result, as has been experienced by other workers on $\{\mathrm{FeNO}\}^{7}$-type chromophores. ${ }^{[39]}$

Fortunately, the existence of the $\left[\mathrm{FeCl}_{3}(\mathrm{NO})\right]^{-}$ion as a chromophore made up of only six atoms also allowed us to apply 'expensive' methods. The results of the study are collected in Table 6. Herein, the experimental data are juxtaposed with computational values from a TD-DFT approach on the TPSSh/def2TZVP level of theory, as well as a $\operatorname{CASSCF}(9,13)$ calculation, state-averaged over 15 spin-allowed and 6 spin-forbidden roots, with a subsequent NEVPT2 treatment of dynamic correlation. A short note on the choice of the active space should be made. In contrast to an adequate description of the ground state which did not need the inclusion of the lone pair on the nitrogen atom, its inclusion was substantial for an appropriate treatment of the excited states.

Our evaluation of the computational results started with the identification of the expected transitions by means of the orbital levels of Figure 10. Excluding the stable MO 42 from those considerations, three excitations each were expected in the $\alpha$ - and the $\beta$-channel.

Thus, $\beta$-spin transitions should occur from the degenerate Fe-NO bonds (MOs 44 and 45) (1) to the degenerate metal-centred MOs of the xy-plane (MOs 46 and 47), (2) to the mainly metal-d( $\left.\mathrm{z}^{2}\right)$-centred $\mathrm{MO} 48$, and (3) to the degenerate couple of Fe-NO antibonds (MOs 49 and 50).

Three $\alpha$-spin transitions may be observed into the degenerate Fe-NO antibonds as the only acceptor orbitals starting from (1) the degenerate xy-plane MOs 46 and 47, (2) the $\mathrm{d}\left(\mathrm{z}^{2}\right)$-centered MO 48, and (3) the $\mathrm{Fe}-\mathrm{NO}$ bonds. These transitions are summarised in the second column of Table 6.

Table 6. 'Label' column: label of the transition as in Figure 12 and Figure 13. 'Transition' column: $b$, ab and $x \mid y$ as defined in Figure 10; ${ }^{4} \mathrm{~b}$ and ${ }^{6} \mathrm{ab}$ refer to a spin-forbidden excitation from the quartet ground state to a sextet excited state. 'WFT' ('Wave Function Theory') column: $\tilde{v} / \mathrm{cm}^{-1}$ (in parentheses: oscillator frequency in atomic units), NEVPT2 $(9,13) /$ def2-TZVP, 15 quartet and 6 sextet state-averaged roots, CPCM $(\varepsilon=\infty)$. 'DFT' column: TD-DFT, $f_{\text {osc }}$ as before, TPSSh/def2-TZVP, CPCM $(\varepsilon=\infty)$. The 'solution' and 'solid' columns refer to the experiments of Figure 12 and Figure 13. 


\begin{tabular}{|c|c|c|c|c|c|}
\hline label & transition & WFT $\left(f_{\text {osc }} / 10^{-5}\right)$ & $\operatorname{DFT}\left(f_{\text {osc }} / 10^{-5}\right)$ & solution & solid \\
\hline to $\mathrm{A}$ & ${ }^{4} \mathrm{~b} \longrightarrow{ }^{6} \mathrm{ab}$ & $\begin{array}{l}16010 \text { (forb.) } \\
16016 \text { (forb.) }\end{array}$ & - & to $\mathrm{A}_{1-3}$ & \\
\hline $\mathrm{A}_{1-3}$ & $\mathrm{~b} \stackrel{\beta}{\longrightarrow} \mathrm{x} \mid \mathrm{y}$ & $\begin{array}{l}16378(0) \\
16692(27) \\
16842(68) \\
16886(37)\end{array}$ & $\begin{array}{l}15405(0) \\
15721(13) \\
17086(13) \\
17100(13) \\
\end{array}$ & $\begin{array}{l}14030 \\
15683 \\
18125\end{array}$ & $\begin{array}{l}13663 \\
14884 \\
17087\end{array}$ \\
\hline B & $\mathrm{b} \stackrel{\beta}{\longrightarrow} \mathrm{z}^{2}$ & $\begin{array}{l}20424(167) \\
20430(167)\end{array}$ & $\begin{array}{l}22408(19) \\
22437(20) \\
\end{array}$ & 21054 & 20674 \\
\hline $\mathrm{C}$ & $\mathrm{b} \stackrel{\beta}{\longrightarrow} \mathrm{ab}$ & $\begin{array}{l}23106(7) \\
23114(6) \\
23166(0) \\
\end{array}$ & $\begin{array}{l}20712(2) \\
20776(2) \\
22756(0) \\
\end{array}$ & 23531 & $\begin{array}{l}22288 \\
23266\end{array}$ \\
\hline $\mathrm{D}$ & $\mathrm{z}^{2} \stackrel{\alpha}{\longrightarrow} \mathrm{ab}$ & $\begin{array}{l}25225(135) \\
25231(136)\end{array}$ & $\begin{array}{l}25493(11) \\
25448(9) \\
25981(78) \\
25977(79) \\
\end{array}$ & 25233 & 25220 \\
\hline \multirow[t]{2}{*}{$\mathrm{E}$} & $\mathrm{x} \mid \mathrm{y} \stackrel{\alpha}{\longrightarrow} \mathrm{ab}$ & $\begin{array}{l}\text { minor part in } \\
\mathrm{b} \stackrel{\alpha}{\longrightarrow} \mathrm{ab} \text { : }\end{array}$ & $\begin{array}{l}26533(102) \\
26571(105) \\
\end{array}$ & \multirow[t]{2}{*}{28183} & \multirow[t]{2}{*}{27185} \\
\hline & $\mathrm{b} \stackrel{\alpha}{\longrightarrow} \mathrm{ab}$ & $29855(348)$ & $27710(96)$ & & \\
\hline
\end{tabular}

In the wave-function approach, most of the calculated transitions were assigned to the expected excitations. No clear contribution to the spectra was obtained for the expected $\mathrm{x} \mid \mathrm{y}$-to-Fe-NO-antibond excitation which was found only as a minor constituent of the strongest transition, the Fe-NO-bond-toantibond excitation in the $\alpha$-channel. Another point was the early onset of measured absorption on the lowenergy end of the spectrum which was hardly mirrored in the calculation. To contribute to this point, we added spin-forbidden quartet-to-sextet excitations to the spin-allowed quartet-to-quartet transitions. As a result, the transition from the global to the sextet ground state occured at a slightly lower energy and may be considered a contribution to the experimental spectra.

In a TD-DFT approach using the hybrid functional TPSSh, the excitations starting from the $\mathrm{x} \mid \mathrm{y}$ MOs were resolved as individual contributions. However, in terms of transition energy, the $\mathrm{B}$ and $\mathrm{C}$ absorptions occured in reversed order, though their intensities showed that the wave-function assignment should be correct.

As a result of this part of the study, each of the transitions weaken the Fe-NO bond and thus may initiate an alteration of the nitrosyl's bonding situation, be it a PLI event or the simple photolysis of the FeNO bond. In agreement with these assignments, the PLI events described below were typically initiated by a $660 \mathrm{~nm}$ laser source which irradiated into the low-energy band A.

This result relies on a specific prerequisite, namely the absence of chromogenic coligands. The property is shared between the title compounds and the aqua-ligated, light-sensitive 'brown-ring' chromophore. ${ }^{[38 \mathrm{a}]}$ In contrast to our study, the resistance of a nitrosyl ligand to NO release on irradiation may result if absorbing coligands are present. ${ }^{[40]}$

Metastable isonitrosyl and the search for side-on nitrosyl isomers

The detailed knowledge of the PLI pathways in the well-understood SNP case provided us with a guide to what may have been expected at most in a PLI study on $\left[\mathrm{FeCl}_{3}(\mathrm{NO})\right]^{-}$. Of the two known PLisomers that can be generated in an SNP crystal, the isonitrosyl (MS1) lies ca. $2 \mathrm{eV}$ above the ground state (GS), whereas the side-on MS2 isomer is ca. $1.5 \mathrm{eV}$ unstable with respect to the GS. The bonding situation in both isomers may be derived from GS bonding. In the ground state's overall low-spin, $S=0$, configuration, 
the two electron pairs in $\mathrm{Fe}-\mathrm{d}(\mathrm{xz})$ and $\mathrm{Fe}-\mathrm{d}(\mathrm{yz})(z$ along the $\mathrm{Fe}-\mathrm{N}-\mathrm{O}$ axis $)$ donate into the NO- $\pi^{*}(\mathrm{x})$ and the NO- $\pi^{*}(y)$ of the nitrosyl ligand - as in our case above. The simple rotation of the NO ligand in the drawing plane by $90^{\circ}$ steps generates alternative, symmetry-allowed $\mathrm{Fe}-\mathrm{NO}$ overlap. In total, the four-lobe pattern of an NO- $\pi^{*}$ antibond allows for four interactions: the GS at $0^{\circ}$, two side-on isomers for 90 and $270^{\circ}$ (MS2) and a linear Fe-O-N-moiety (MS1, isonitrosyl) for the $180^{\circ}$ turn (Figure S11 in the SI). Performing this rotation quantitatively in a relaxed scan, the global minimum close to $0^{\circ}$ rotation $\left(\mathrm{Fe}-\mathrm{N}-\mathrm{O}=180^{\circ}\right)$ for the GS and the local MS1 and MS2 minima are supplemented with transition states between them which define activation barriers for the MS $\rightarrow \mathrm{GS}$ relaxation of almost $1 \mathrm{eV}^{[2 \mathrm{c}]}$

To identify the hoped-for new IR bands arising in the course of PLI-directed experiments on the title compounds, we started our investigation with an angle-scan for the $\left[\mathrm{FeCl}_{3}(\mathrm{NO})\right]^{-}$ion. Figure 16 (red circles) shows the result which was obtained on the BP86/def2-TZVP level of theory. Approximately $1.2 \mathrm{eV}$ above the GS, an isonitrosyl, MS1, species defines a local minimum. Contrary to SNP, only a single transition state has to be surmounted on the entire GS $\rightarrow$ MS1 path, and no indication was found for a second local minimum of a side-on, MS2, state. Moreover, the activation barrier for the MS1 $\rightarrow$ GS relaxation amounted to only $0.3 \mathrm{eV}$ and thus was substantially lower than for SNP. The IR signature of the MS1 species, as a guide to the experimental work, was determined on the same level as $\tilde{v}=1598 \mathrm{~cm}^{-1}$ for the $\mathrm{O}-\mathrm{N}$ stretch. An important note has to be made: in order to adequately compare energies referring to two substances (our MNIC and $\mathrm{SNP}$ ), we used numbers from DFT calculations in both cases. Experimental values for the energies of the PL-isomers as well as activation energies are available for SNP and are usually substantially smaller than the calculated ones. ${ }^{[41]}$

The population of the isonitrosyl (MS1) state in solid $\mathrm{A}\left[\mathrm{FeCl}_{3}(\mathrm{NO})\right]$ salts

The determining factors in the search for linkage isomers of the $\left[\mathrm{FeCl}_{3}(\mathrm{NO})\right]^{-}$ion arose out of the DFT scan. An MS1 state appeared to be tangible, though the activation barrier for its decay to the ground state was unusually low. The experimental setup thus included the lowest accessible temperatures. Fortunately, the available equipment allowed for cooling to $9 \mathrm{~K}$. At this temperature, the expected IR frequency for an MS1 isomer of about $1600 \mathrm{~cm}^{-1}$ was detected for various salts of the formula $\mathrm{A}^{+}\left[\mathrm{FeCl}_{3}(\mathrm{NO})\right]^{-}$, namely for $\mathrm{A}^{+}=$ $\mathrm{NMe}_{4}{ }^{+}, \mathrm{NBnMe}_{3}{ }^{+},\left[\mathrm{Co}(\mathrm{cp})_{2}\right]^{+}, \mathrm{PPh}_{4}{ }^{+}, \mathrm{AsPh}_{4}{ }^{+}$, and $\mathrm{Mephaz}^{+}$(5-methyl-phenazinium). For these cations, irradiation with a $660 \mathrm{~nm}$ laser source, i.e., irradiation into band A of Figure 12, gave rise to IR absorptions of $1627 / 1635,1550,1572,1571,1580$, and $1575 \mathrm{~cm}^{-1}$, respectively. After the population by irradiation, the MS1 relaxed in the course of about 2 to 15 minutes to the ground state, depending on the counterion.

An overview of a PLI experiment is shown in Figure 14 with $\mathrm{NMe}_{4}\left[\mathrm{FeCl}_{3}(\mathrm{NO})\right]$ as an example. The progress of the relaxation of the MS1 over a period of time of $4 \mathrm{~min}$ is depicted in Figure 15. 


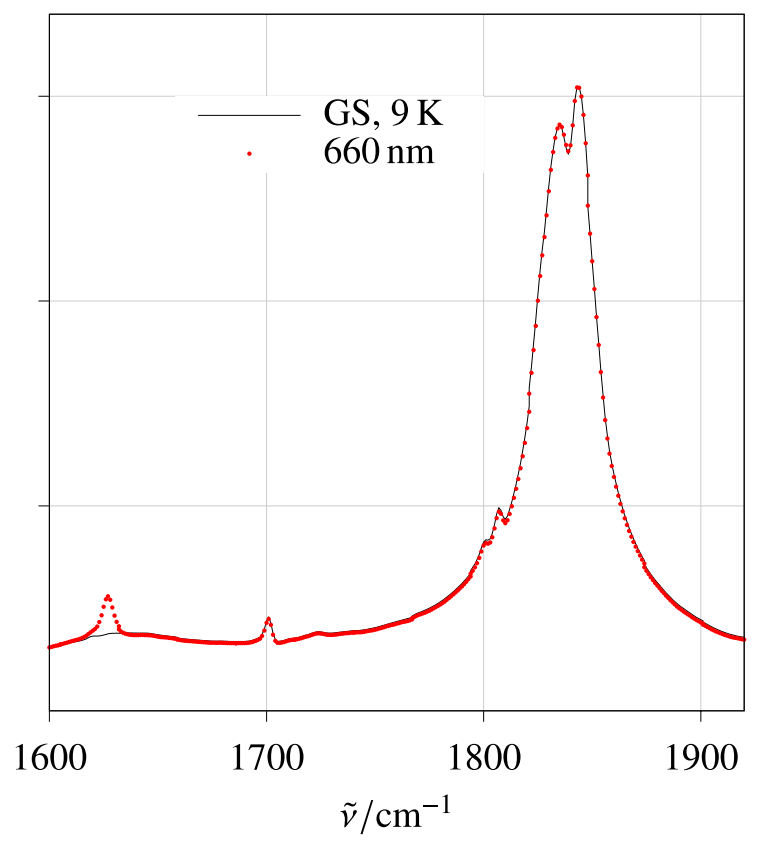

Figure 14. An overview over the PLI experiment on $\mathrm{NMe}_{4}\left[\mathrm{FeCl}_{3}(\mathrm{NO})\right]$. At $9 \mathrm{~K}$, the $\mathrm{Fe}-\mathrm{NO}$ valence vibration is slightly split. On irradiation with a 660-nm laser, a new small absorption arised at about $1630 \mathrm{~cm}^{-1}$. The relaxation of this band on leaving the sample un-irradiated at $9 \mathrm{~K}$ is shown in Figure 15.

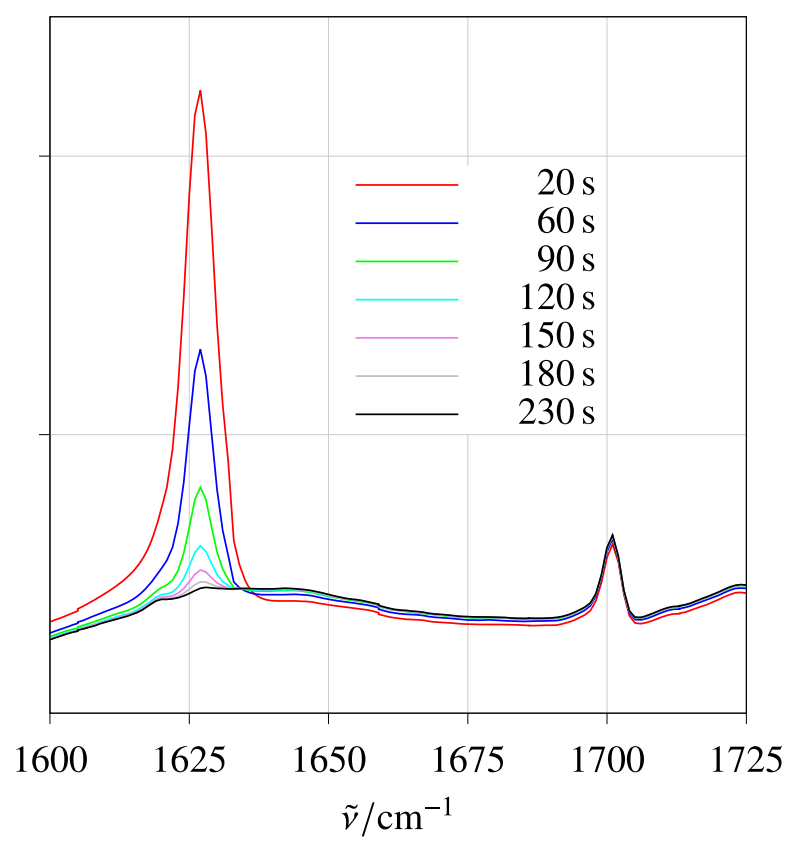

Figure 15. The relaxation of the excited state of $\mathrm{NMe}_{4}\left[\mathrm{FeCl}_{3}(\mathrm{NO})\right]$ after irradiation with 660 -nm laser light at $9 \mathrm{~K}$ in the course of about $4 \mathrm{~min}$.

\section{Peculiarities of quartet- $\{\mathrm{FeNO}\}^{7} \mathrm{PLI}$}

After the successful match of DFT analysis and experiment, a closer look at the differences between the electronic structure of the SNP anion and the $\left[\mathrm{FeCl}_{3}(\mathrm{NO})\right]^{-}$ion seemed essential. A notable detail, however, which facilitates the discussion should be mentioned first.

To radically simplify the theoretical treatment of a $\{\mathrm{FeNO}\}^{n}$ species, one could omit all coligands. For the $\{\mathrm{FeNO}\}^{7}(S=3 / 2)$ species in question, Reiher used that approach to analyse the triatomic $[\mathrm{Fe}(\mathrm{NO})]^{2+}$ ion to allow for high-level methods. ${ }^{[42]}$ If his restriction (four point charges around the central metal and a fixed 
$\mathrm{Fe}-\mathrm{N}-\mathrm{O}$ angle) is lifted, the frontier orbitals of a linear $[\mathrm{Fe}(\mathrm{NO})]^{2+}$ ion emerge to (1) a couple of doubly occupied Fe-NO $\pi$-bonding levels, (2) a couple of singly occupied metal-only orbitals labelled d(xy) and $\mathrm{d}\left(\mathrm{x}^{2}-\mathrm{y}^{2}\right)$ if the $\mathrm{Fe}-\mathrm{N}-\mathrm{O}$ axis is chosen as $z$, and (3) the singly occupied, metal-centered Fe-d $\left(\mathrm{z}^{2}\right)-\mathrm{NO} \sigma$ antibond as the HOMO. In other words, the $C_{3}$-symmetrical arrangement of three coligands, as in the $\left[\mathrm{FeCl}_{3}(\mathrm{NO})\right]^{-}$ion, shares the level splitting scheme of the simple triatomic core.

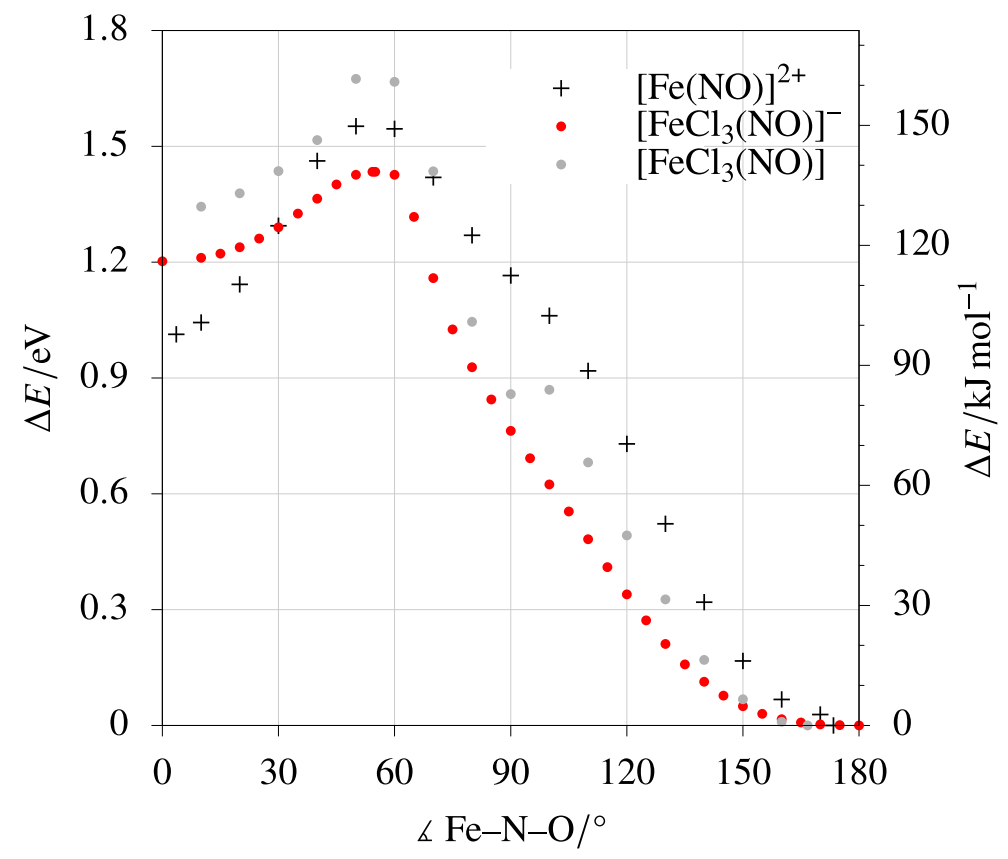

Figure 16. Relaxed surface scans using the $\mathrm{Fe}-\mathrm{N}-\mathrm{O}$ angle as the scan variable. Red circles: the quartet- $\{\mathrm{FeNO}\}^{7}$ ion $\left[\mathrm{FeCl}_{3}(\mathrm{NO})\right]^{-}$; grey circles: the triplet- $\{\mathrm{FeNO}\}^{6}$ species $\left[\mathrm{FeCl}_{3}(\mathrm{NO})\right]$; crosses: the triatomic quartet- $\{\mathrm{FeNO}\}^{7}$ ion $[\mathrm{Fe}(\mathrm{NO})]^{2+}$. Energies apply to the respective ground-state energy set to 0 .

The similarity of the electronic configuration of the $\left[\mathrm{FeCl}_{3}(\mathrm{NO})\right]^{-}$ion to its $[\mathrm{Fe}(\mathrm{NO})]^{2+}$ core is underlined by a Fe-N-O angle scan for the triatomic species as well (crosses in Figure 16). As a common feature, a local MS2 minimum is absent for both species. In contrast, the MS1 $\rightarrow$ GS barrier is markedly higher for the triatomic core.

To understand the key point, which is the absence of an MS2 state, a comparison of the configurations of the SNP anion and the quartet- $\{\mathrm{FeNO}\}^{7}$ species was useful. In SNP, the octahedral environment of the central metal with strong-field ligands safely fixes the d-orbital alignment (for a closer discussion of the necessary conditions for a PLI event see Ref. ${ }^{[43]}$ ). Thus, for example, in the $x z$ plane of the SNP anion, overlap between $\mathrm{Fe}-\mathrm{d}(\mathrm{xz})$ and $\mathrm{NO}-\pi^{*}(\mathrm{x})$ is clearly maximised for the above-mentioned $90^{\circ}$ jumps only. To stay with the example $x z$ plane, the metal orbitals are effectively fixed, in the quartet- $\{\mathrm{FeNO}\}^{7}$ species, only by the nitrosyl strong-field ligand. If the nitrosyl ligand starts to rotate, the metal orbitals follow. Due to the increasingly imperfect overlap, the energy rises smoothly on rotation. The energetic landscape is thus much flatter than in the case of fixed metal orbitals. An alternative view may be developed by looking for orbital mixing. Mixing the $\mathrm{d}(\mathrm{xz})$ orbital and the $\mathrm{d}\left(\mathrm{z}^{2}-\mathrm{x}^{2}\right)$ part of a $\mathrm{d}\left(\mathrm{z}^{2}\right)=\mathrm{d}\left(2 \mathrm{z}^{2}-\mathrm{x}^{2}-\mathrm{y}^{2}\right)$ orbital allows the adjustment of this pair of four-leaf-clover-shaped orbitals at any angle in the $x z$ plane.

The occupation of this orbital pair with three electrons in the quartet- $\{\mathrm{FeNO}\}^{7}$ species might be regarded as crucial. In the $\{\mathrm{FeNO}\}^{6}$ case $\mathrm{SNP}, \mathrm{d}(\mathrm{xz})$ and $\mathrm{d}\left(\mathrm{z}^{2}\right)$ are not only spatially fixed. Moreover, the former is doubly occupied, and the latter is empty. In order to check the significance of a singly occupied Fe$\mathrm{d}\left(\mathrm{z}^{2}\right)$ orbital in the $\{\mathrm{FeNO}\}^{7}$ species, a scan was performed for a tentative species that lacked this specific 
electron, i.e., a triplet $\left[\mathrm{FeCl}_{3}(\mathrm{NO})\right]$ molecule with the same configuration as in Figure 10 but with MO48 empty. The result is shown in Figure 16 (grey circles). In fact, a dent becomes visible along the GS $\rightarrow \mathrm{TS}$ path, but no distinct local MS2 minimum. (A final fourth scan on the tentative species's $[\mathrm{Fe}(\mathrm{NO})]^{3+}$ core was hampered since this threefold-charged species dissociated to $\mathrm{Fe}^{2+}$ and $\mathrm{NO}^{+}$on the chosen level of theory.)

As a result, we conclude that the distinct fixing of a central metal's $d$ electrons is a prerequisite to catch all the expected photoinduced linkage isomers of a nitrosylmetal complex. The depopulation of the $\sigma$ antibonding HOMO of a $\{\mathrm{FeNO}\}^{7}$ species supports the possibility of stabilising an MS2 state but is not a sufficient criterion. To lend significance to the peculiarities of SNP and other MS2-producing systems, it should be noted that it is not only a high crystal-field-splitting that creates a diamagnetic low-spin ground state with both well-fixed orbitals and an empty $\mathrm{d}\left(\mathrm{z}^{2}\right)$, but the symmetry of the entire species is decisive. Thus, any $\{\mathrm{FeNO}\}^{6}$ species with degenerate or close-to-degenerate $\mathrm{d}(\mathrm{xy}) / \mathrm{d}\left(\mathrm{x}^{2}-\mathrm{y}^{2}\right)$ orbitals will lack a diamagnetic $S=0$ state irrespective of the coligands' strength (see the next paragraph).

\section{The population of an anion-to-cation charge-transfer state}

$\mathrm{PPN}\left[\mathrm{FeCl}_{3}(\mathrm{NO})\right]$ was a special case. For the $\mathrm{PPN}^{+}$counterion, a similar IR-spectroscopic signature was observed in terms of population and decay behaviour as for the MS1-positive samples at first glance. At $9 \mathrm{~K}$, exposure to light of $635 \mathrm{~nm}$ wavelength, the $\mathrm{N}-\mathrm{O}$ stretch at $1809 \mathrm{~cm}^{-1}$ was depopulated and, at the same time, a new band arose at an unusually high wave number of $1868 \mathrm{~cm}^{-1}$ (Figure 17). Thus, the frequency of the newly observed $\mathrm{N}-\mathrm{O}$ stretch did not match the typical red shift of an MS1 (or MS2) state. Warming irradiated samples to $40 \mathrm{~K}$ made the new absorption vanish. At $9 \mathrm{~K}$, the new state relaxed in the course of about an hour, i.e., much more slowly than the MS1 described above, to the ground state without intensity loss of the latter.

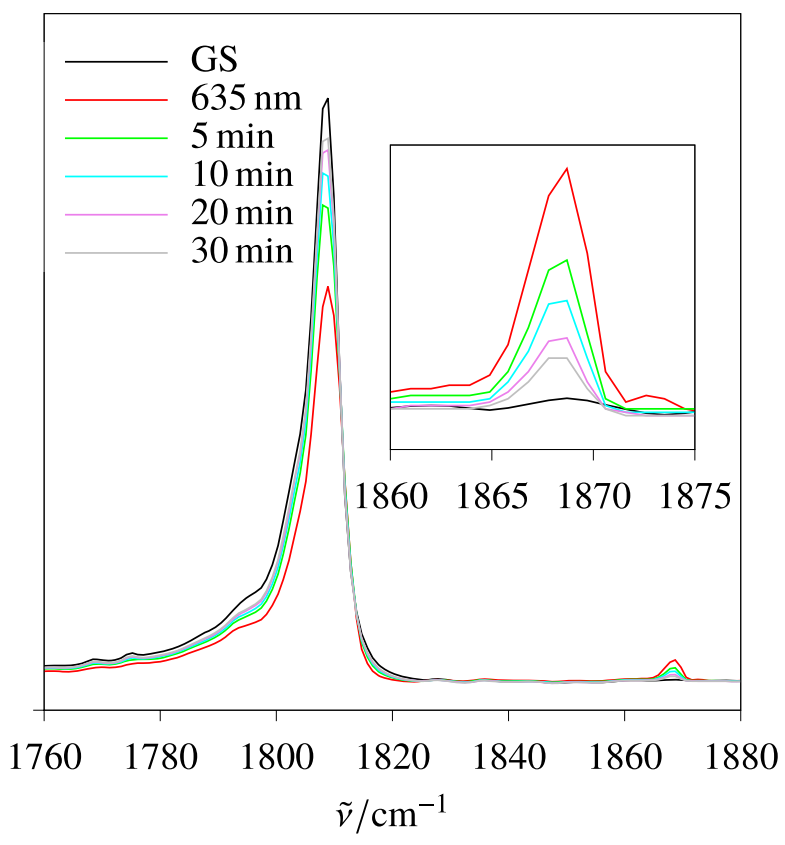

Figure 17. Population at $635 \mathrm{~nm}$ and subsequent relaxation of small amounts of a tentative one-electron transfer couple $\mathrm{PPN}^{\cdot}+\left[\mathrm{FeCl}_{3}(\mathrm{NO})\right]$ in solid $\mathrm{PPN}^{+}\left[\mathrm{FeCl}_{3}(\mathrm{NO})\right]^{-}$. Note the decrease and the re-constitution of the major ground-state $\mathrm{N}-\mathrm{O}$ stretch, and the population and relaxation of the excited state at $1868 \mathrm{~cm}^{-1}$.

An approach to the nature of the excited state was made by means of the DFT screening of a number of tentative structurally and electronically excited states. As a result, two matches were found, both being 
oxidation products of the parent $\left[\mathrm{FeCl}_{3}(\mathrm{NO})\right]^{-}$ion, namely the electroneutral $\{\mathrm{FeNO}\}^{6}$ complex $\left[\mathrm{FeCl}_{3}(\mathrm{NO})\right]$. Since the crystals of $\mathrm{PPN}\left[\mathrm{FeCl}_{3}(\mathrm{NO})\right]$ did not contain any solvent molecules or other cocrystallised species, we assumed the transfer of an electron to the $\mathrm{PPN}^{+}$counterion with the formation of a $\mathrm{PPN}^{*}$ radical as the excitation mechanism.

This assignment was supported by a closer look at the PPN part of the IR spectra. At the same time when the excited state was populated in terms of $\tilde{v}(\mathrm{NO})$, various PPN-related bands were depopulated in favour of small shoulders to these bands. The latter vanished on relaxation to the ground state whereas the main band was restored. As an example, the SI shows this reaction sequence for a band at $1245 \mathrm{~cm}^{-1}$ which developed a shoulder close to $1258 \mathrm{~cm}^{-1}$ (this band was assigned to the asymmetric $\mathrm{P}-\mathrm{N}-\mathrm{P}$ valence vibration in Ref. ${ }^{[44]}$ ).

The two species from the DFT screening differed in their spin state, a triplet and a quintet. Both $\mathrm{N}-\mathrm{O}$ stretches matched the experimental value satisfactorily: $1884 \mathrm{~cm}^{-1}$ for the triplet, $1866 \mathrm{~cm}^{-1}$ for the quintet. In terms of atomic distances and bond angles, the transition to the triplet is more conservative. In particular, the FeNO moiety keeps close to linearity $\left(167^{\circ}\right)$, while the minimum quintet structure showed a less obtuse angle of $128^{\circ}$. Geometrical details of both calculations are collected in the SI. In terms of energy, the triplet was approximately $20 \mathrm{~kJ} \mathrm{~mol}^{-1}$ stable with respect to the quintet.

A more significant difference of the spin isomers arose for the electron distribution in the respective species. On the one hand, the triplet isomer is obtained by the removal of an electron from the ground state's $\mathrm{HOMO}$, the $\mathrm{d}\left(\mathrm{z}^{2}\right)$ orbital, leaving both covalent $\mathrm{Fe}-\mathrm{NO} \pi$ bonds intact. On the other hand, the formulation of a quintet state requires the withdrawal of a $\beta$-spin electron from one of the $\mathrm{Fe}-\mathrm{NO} \pi$ bonds. Using a simplified description of equally shared $\pi$-electron pairs in a $\mathrm{Fe}^{\mathrm{III}}-\mathrm{NO}^{-}$fragment with the $\pi$ bonds' $\alpha$ spins at the metal and the $\beta$ spins at the $\mathrm{NO}^{-}$ligand, triplet formation corresponds to a metal-centered, and quintet formation to a ligand-centered oxidation. (Researchers who prefer this $\mathrm{Fe}^{\mathrm{III}}-\mathrm{NO}^{-}$formulation, would term the triplet state $\mathrm{Fe}^{\mathrm{IV}}-\mathrm{NO}^{-}$.)

Among those two choices, we saw the higher probability for the $\{\mathrm{FeNO}\}^{6}(S=1)$ species. It is more stable than the $\left\{\mathrm{FeNO}^{6}(S=2)\right.$ spin isomer (which, however, is not an expedient criterion for an excited state). As a better argument, the $\mathrm{Fe}-\mathrm{NO} \pi$ bonds are preserved in the triplet state. Finally, there was evidence from the literature that a $\{\mathrm{FeNO}\}^{6}(S=1)$ state is tangible for suited ligands. Hence, the Lehnert group reported on the preparation of a triplet- $\{\mathrm{FeNO}\}^{6}$ complex by the metal-centered oxidation of an $\{\mathrm{FeNO}\}^{7}$ precursor which shares the $C_{3}$ symmetry of the coligand part (a tetradentate nitrogen chelator) with the $\left[\mathrm{FeCl}_{3}(\mathrm{NO})\right]^{-}$ion. ${ }^{[45]}$ As mentioned above, it should be noted that neither the tentative $\left[\mathrm{FeCl}_{3}(\mathrm{NO})\right](S=1)$ species nor Lehnert's complex is able to develop an $S=0$ spin isomer due to the degenerate x|y couple of Figure 10 whose origin is solely the $C_{3}$ symmetry of the coligand sphere. (Since $S=1$ or 2 are, thus, the only possible spin states of a $\{\mathrm{FeNO}\}^{6}$ species with threefold symmetry, the triplet state might not be termed 'high spin'. ${ }^{[45]}$ )

Eventually, we also looked for a charge-transfer state for the other cations employed. As a result, the salt with the Mephaz ${ }^{+}$counterion showed a matching IR-signature both for the excitation into an MS1 state and into an $\left[\mathrm{FeCl}_{3}(\mathrm{NO})\right]^{-} \rightarrow\left[\mathrm{FeCl}_{3}(\mathrm{NO})\right]+\mathrm{e}^{-}$state. Since the electron of the latter process reduces the counterion, the cobaltocenium salt appeared as particularly suited for this process. However, an MS1 isomer was the only excited form that was detected after irradiation of $\left[\mathrm{Co}(\mathrm{cp})_{2}\right]\left[\mathrm{FeCl}_{3}(\mathrm{NO})\right]$. 


\section{Primary physical investigation of $\left\{\mathrm{Fe}(\mathrm{NO})_{2}\right\}^{9}$-type DNICs: $\mathrm{A}\left[\mathrm{FeCl}_{2}(\mathrm{NO})_{2}\right]$ salts}

In the DNIC part of the physical characterisation of the title compounds we wish to present first results in the sense of a proof-of-principle. In analogy to the $\mathrm{A}\left[\mathrm{FeCl}_{3}(\mathrm{NO})\right]$-type MNICs above, irradiation of the respective $\mathrm{A}\left[\mathrm{FeCl}_{2}(\mathrm{NO})_{2}\right]$-type DNICs exhibited photo-induced linkage isomerism. In the following section, we present the state of the UV-vis-spectrocopical characterisation with a satisfactory experimental status but with a preliminary computational investigation. Subsequently, we report on the detection of a single MS1type photo-isomer in a still low population.

UV-vis spectra of two salts $\mathrm{A}\left[\mathrm{FeCl}_{2}(\mathrm{NO})_{2}\right]\left(\mathrm{A}=\mathrm{NMe}_{4}, \mathrm{PPN}\right)$

The Gauss-deconvoluted UV-vis spectrum of the red-brown solutions of $\mathrm{NMe}_{4}\left[\mathrm{FeCl}_{2}(\mathrm{NO})_{2}\right]$ in acetone is shown in Figure 18. As the mere optical inspection suggested, the optical density of the solutions was lower than that of the respective MNIC at the same molar concentration (compare the about twice as large $\varepsilon$ values in the visible range of Figure 12).

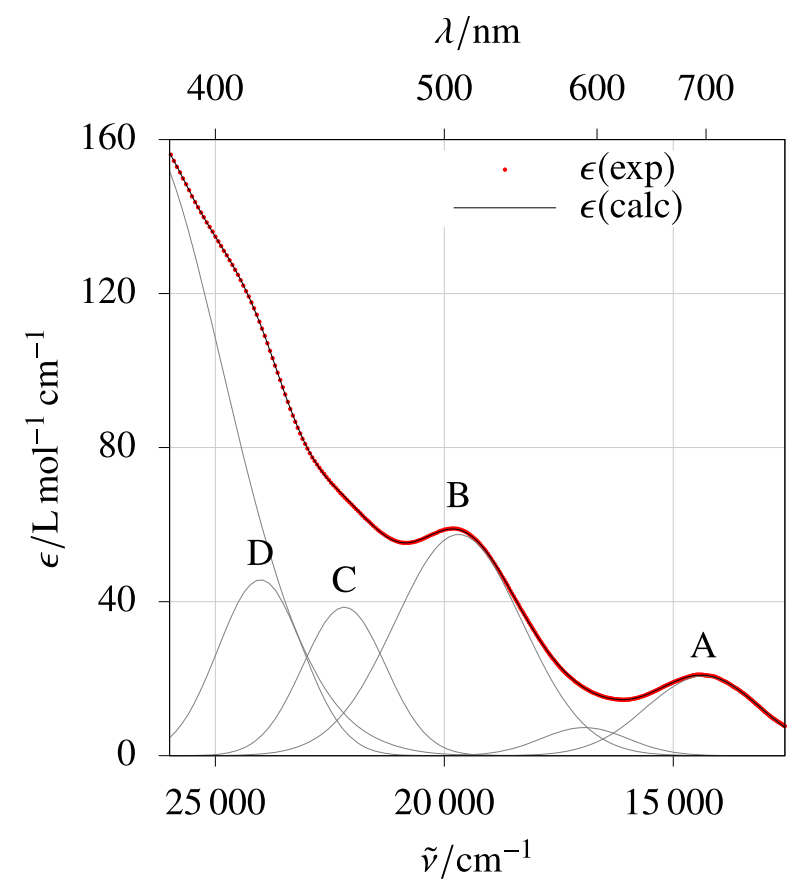

Figure 18. UV-vis spectrum of $\mathrm{NMe}_{4}\left[\mathrm{FeCl}_{2}(\mathrm{NO})_{2}\right]$ in methanol. The maxima of the visual range fit to $14336(\mathrm{~A})$, 16735,19446 (B), 21713, $25163 \mathrm{~cm}^{-1}$ (C). 


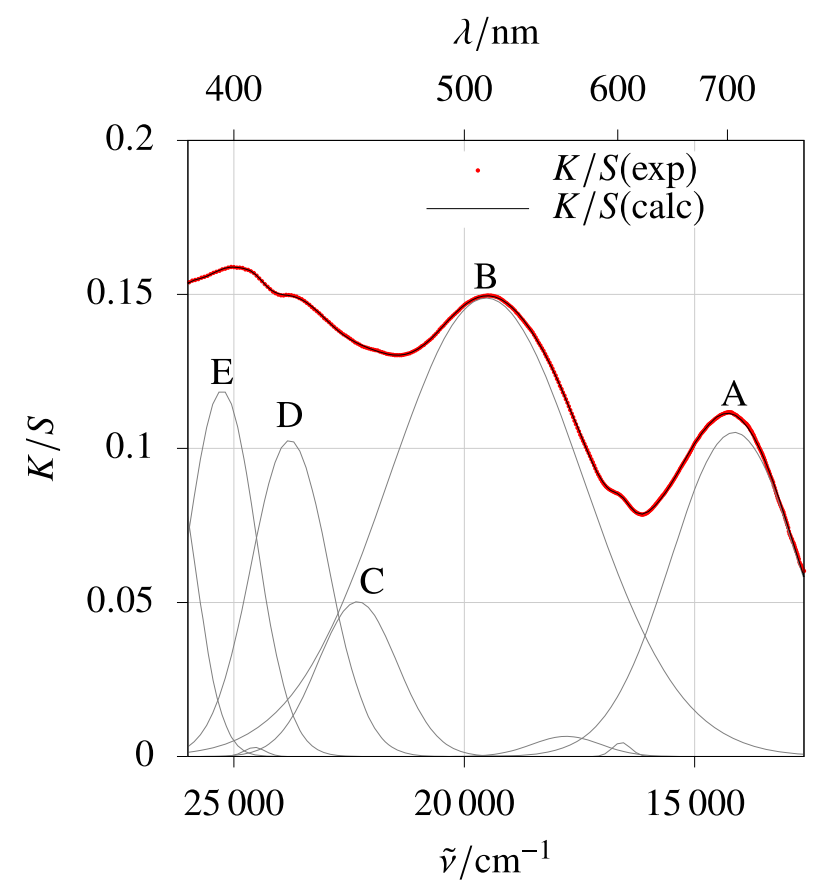

Figure 19. UV-vis spectrum of solid $\mathrm{NMe}_{4}\left[\mathrm{FeCl}_{2}(\mathrm{NO})_{2}\right]$, diluted with $\mathrm{BaSO}_{4}$. The maxima of the visual range fit to 14336 (A), 16735,19446 (B), 21713, $25163 \mathrm{~cm}^{-1}$ (C).

Figure 19 shows the reflectance spectrum of the same substance with a satisfying match of the major absorption bands of the visible region.

\section{Computational analysis of the DNIC UV-vis spectra}

A primary classification of the electronic transitions should start from the MO scheme in Figure 11. Thus, four classes of spin-allowed one-electron transitions were expected on the basis of the MO sequence. First, in the $\beta$-regime, two transition types were expected, the one moving an electron from the $\mathrm{Fe}-\mathrm{NO}$ bonds to the $\mathrm{d}\left(\mathrm{z}^{2}\right)$ orbital, whereas the other should be an excitation from the same bonds to the respective antibonds. Second, in the $\alpha$ regime, two more transitions should excite the $\mathrm{d}\left(\mathrm{z}^{2}\right)$ spin to the $\mathrm{Fe}-\mathrm{NO}$ antibonds, and a bond electron to an antibond. A comparison of Figure 10 and Figure 11 shows, that both the $\mathrm{Fe}-\mathrm{NO}$ bonds as well as the antibonds comprise a markedly extended energy range in the case of the DNIC. A larger number of non-degenerate transitions was thus expected to be typical for the DNIC chromophore, resulting in broad and superimposing spectral features.

On the first attempt, the TD-DFT study ended unsatisfactorily. The identification of the individual transitions was ambiguous in terms of a marked dependence of the calculated spectra on the used functionals. In fact, the same experience was made with the MNIC analogue (see above). In this sense, the reasonable match between wave-function and density-functional methods in Table 7 should be seen with reservations. It was simply the TPSSh functional (not BP86, not $\omega$ B97X-D3) which showed a closer agreement (similar to B3LYP) and was thus chosen for the table entries.

In Table 7, an attempt is made to interpret the computational results. Since each group of transitions span a large range of energy due to the reasons given above, the calculated intensity in terms of the oscillator frequency was taken as a guideline. Thus, weak transitions were skipped, and, as a result, peak A showed no match with any spin-allowed transition. In the wave-function part, however, transitions from the dublet ground state to excited quartet states lay in the wave-number range in question. In contrast to the MNIC analysis, peak B thus appeared to stem from the lowest-energy spin-allowed transition. As a common feature 
of MNIC and DNIC excitation, the characteristic band B belonged to a Fe-NO-bond-to-metal transition.

The remaining assignments suffered from the expected and actually observed broadness of the DNIC bands. The assignments made in Table 7 thus should be taken only as a rough guideline for further investigations.

Table 7. 'Label' column: label of the transition as in Figure 18 and Figure 19. 'Transition' column: $b$, ab and $z^{2}$ are used in analogy to Figure $10 ;{ }^{4} \mathrm{~b}$ and ${ }^{6} \mathrm{ab}$ refer to a spin-forbidden excitation from the quartet ground state to a sextet excited state. 'WFT' column: $\tilde{v} / \mathrm{cm}^{-1}$ (in parentheses: oscillator frequency in atomic units), NEVPT2(9,13)/def2-TZVP, 15 quartet and 6 sextet state-averaged roots, CPCM $(\varepsilon=\infty)$. 'DFT' column: TD-DFT, TPSSh/def2-TZVP, CPCM $(\varepsilon=\infty)$. The 'solution' and 'solid' columns refer to the experiments of Figure 18 and Figure 19; the tabulated solution peak at $10905 \mathrm{~cm}^{-1}$ is outside the range of Figure 18 with an intensity of about a tenth of peak A.

\begin{tabular}{|c|c|c|c|c|c|}
\hline label & transition & WFT $\left(f_{\text {osd }} / 10^{-5}>1\right)$ & $\operatorname{DFT}\left(f_{\text {osc }} / 10^{-5}>20\right)$ & solution & solid \\
\hline A & ${ }^{2} \mathrm{~b} \longrightarrow{ }^{4} \mathrm{ab}$ & $\begin{array}{l}11698 \text { (forb.) } \\
13934 \text { (forb.) }\end{array}$ & - & $\begin{array}{l}10905 \\
14343 \\
\end{array}$ & 14139 \\
\hline B & $\mathrm{b} \stackrel{\beta}{\longrightarrow} \mathrm{z}^{2}$ & $\begin{array}{l}16295(25) \\
18880(307) \\
23035(67) \\
\end{array}$ & $\begin{array}{l}16169(58) \\
18208(260)\end{array}$ & 19688 & 19524 \\
\hline \multirow[b]{2}{*}{$\mathrm{C}$} & $\mathrm{b} \stackrel{\beta}{\longrightarrow} \mathrm{ab}$ & $23846(56)$ & & \multirow[b]{2}{*}{22186} & \multirow[b]{2}{*}{22317} \\
\hline & $\mathrm{z}^{2} \stackrel{\alpha}{\longrightarrow} \mathrm{ab}$ & $\begin{array}{l}23363(103) \\
24996(22) \\
\end{array}$ & $23917(603)$ & & \\
\hline $\mathrm{D}, \mathrm{E}$ & $\mathrm{b} \stackrel{\alpha}{\longrightarrow} \mathrm{ab}$ & $\begin{array}{l}25324(400) \\
25552(40) \\
26769(251) \\
\end{array}$ & $\begin{array}{l}26271(640) \\
26650(1481) \\
28355(30) \\
\end{array}$ & 24016 & $\begin{array}{l}23789 \\
25256\end{array}$ \\
\hline
\end{tabular}

The population of a bent isonitrosyl state in solid $\mathrm{A}\left[\mathrm{FeCl}_{2}(\mathrm{NO})_{2}\right]$ salts

Irradiation of the $\mathrm{NMe}_{4}$ and the PPN salts at a low temperature of $10 \mathrm{~K}$ showed the population of the same state in both salts which was characterised by a new IR band above the ground state's bands and a second band distinctly below the GS range. Attempts to match this pattern with a PL-isomer yielded the identification of two isomers, on the BP86/def2-TZVP level, that form local minima on the hypersurface of a $\left[\mathrm{FeCl}_{2}(\mathrm{NO})_{2}\right]^{-}$ion. These two isomers were derived from the $\mathrm{GS}$ by switching one of the NO ligands to the

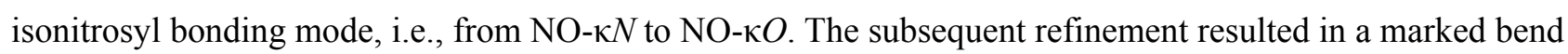
of the $\mathrm{Fe}-\mathrm{O}-\mathrm{N}$ fragment towards the $\mathrm{Fe}-\mathrm{N}-\mathrm{O}$ group, but the IR signature of this species was far removed from the experiment. In a subsequent attempt, the $\mathrm{Fe}-\mathrm{O}-\mathrm{N}$ moiety was bent to the same extent but outwards from the second $\mathrm{Fe}-\mathrm{N}-\mathrm{O}$ group and, again, a local minimum resulted (Figure 20). In this case, we achieved a satisfying match with the experimental values (Table 8).

Table 8. New $\mathrm{N}-\mathrm{O}$ valence-vibration bands in $\mathrm{A}\left[\mathrm{FeCl}_{2}(\mathrm{NO})_{2}\right]\left(\mathrm{A}=\mathrm{NMe}_{4}, \mathrm{PPN}\right)$ after irradiation; the 'calc.' row shows values from a BP86/def2-TZVP calculation.

\begin{tabular}{lll}
\hline & $\tilde{v}(\mathrm{FeO}-\mathrm{N})$ & $\tilde{v}(\mathrm{FeN}-\mathrm{O})$ \\
\hline $\mathrm{NMe}_{4}$ & 1398 & 1775 \\
$\mathrm{PPN}$ & 1406 & 1755 \\
calc. & 1409 & 1738 \\
\hline
\end{tabular}

Thus, photoinduced linkage isomerism is also a phenomenon in the DNIC, specifically in the $\left\{\mathrm{Fe}(\mathrm{NO})_{2}\right\}^{9}$, class. Future work is expected to clarify differences between MNIC and DNIC PLI. Though the new DNIC states are poorly populated in our current experiments, they de-populate at markedly higher temperatures such as those usually found for other PLI-active compounds such as SNP. 


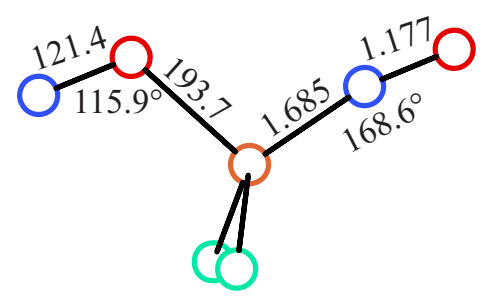

Figure 20. Bonding parameters of a 'bent MS1' local minimum structure of the $\left[\mathrm{FeCl}_{2}(\mathrm{NO})_{2}\right]^{-}$ion. The isomer is $142.7 \mathrm{~kJ} \mathrm{~mol}^{-1}(1.48 \mathrm{eV})$ unstable with respect to the ground state on the BP86/def2-TZVP level.

\section{Experimental Section}

\section{Chemistry}

For some procedures, a $\mathrm{pH}$ value is given. These values serve as a very rough guide; they were obtained by simply dipping indicator paper into the alcoholic solutions. The same values were obtained for dry and water-wetted paper.

\section{A standard (ferrous) route to $\mathrm{A}\left[\mathrm{FeCl}_{3}(\mathrm{NO})\right]$ salts}

In a Schlenk flask, a mixture of ferrous chloride tetrahydrate $(81.1 \mathrm{mg}, 0.500 \mathrm{mmol}, 1$ eq. $)$ and the respective chloride $(0.500 \mathrm{mmol}, 1$ eq. $)$ was dissolved in deoxygenated methanol $(3 \mathrm{~mL})$ to a clear yellow solution. The solution was treated with gaseous $\mathrm{NO}$ at room temperature for 2-10 min. For $\mathrm{A}=\mathrm{PPh}_{4}, \mathrm{AsPh}_{4}$, and PPN, green crystals precipitated in the course of NO treatment. The isolated yield after filtration and washing with diethyl ether was at least $90 \%$. For $\mathrm{A}=\mathrm{NMe}_{4}, \mathrm{NEt}_{4}, \mathrm{NBnMe}_{3}$, and Mephaz, the solution was cooled to $5{ }^{\circ} \mathrm{C}$. In the course of days to months, green crystals formed (see SI). For all counterions, the product crystals were stable to air.

\section{[Co(cp)2]}

A mixture of $\mathrm{FeCl}_{3}(17 \mathrm{mg}, 0.1 \mathrm{mmol})$ and cobaltocene $(20 \mathrm{mg}, 0.1 \mathrm{mmol})$ was dissolved in deoxygenated methanol $(5 \mathrm{~mL})$, then the solution was treated with gaseous $\mathrm{NO}$ at room temperature for 2-10 minutes. The brown solution turned deeper and small green crystals were obtained after keeping in $5{ }^{\circ} \mathrm{C}$ in refrigerator for about one week. The green crystals were collected by filtration and washed with diethyl ether. The green crystals were stable in air (yield: $40 \%$ ).

\section{The ferric route to $\mathrm{A}\left[\mathrm{FeCl}_{3}(\mathrm{NO})\right]$ salts}

Note that the description of the ferric route to chlorido-MNICs is intended to demonstrate charactistic reactivity patterns. It is not recommended as a method to prepare chlorido-MNIC salts in good yield and purity!

Quickly crystallising, Fe ${ }^{\mathrm{III}}$-contaminated samples were obtained by means of a procedure that is exemplified for $\mathrm{NMe}_{4}{ }^{+}$as the counterion. A mixture of ferric chloride $(99.4 \mathrm{mg}, 0.500 \mathrm{mmol})$ and tetramethylammonium chloride $(54.8 \mathrm{mg}, 0.500 \mathrm{mmol})$ was dissolved in deoxygenated methanol (3 $\mathrm{mL})$. The solution was treated with $\mathrm{NO}$ gas at room temperature for 2-10 min to obtain small green crystals of largely $\mathrm{NMe}_{4}\left[\mathrm{FeCl}_{3}(\mathrm{NO})\right]$ at the liquid:gas interface $(42 \%$ yield after filtration and washing with

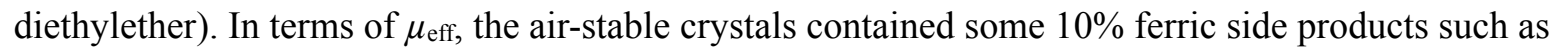
$\mathrm{NMe}_{4}\left[\mathrm{FeCl}_{4}\right]$. Note the shorter crystallisation time also for salts with smaller counterions in comparison to the standard route to the pure products! 
Samples free of magnetically detectable ferric contaminations formed when rapid crystallisation (presumably starting from less soluble $\mathrm{A}\left[\mathrm{FeCl}_{4}\right]$ seeds) was prohibited by sufficient dilution. The $\mathrm{PPN}^{+}$ counterion is used for this example: a mixture of ferric chloride (32 $\mathrm{mg}, 0.20 \mathrm{mmol}$ ) and bis(triphenylphosphane)iminium chloride $(115 \mathrm{mg}, 0.20 \mathrm{mmol}$ ) was dissolved in deoxygenated methanol $(20 \mathrm{~mL})$. The solution was treated with gaseous $\mathrm{NO}$ at room temperature for $5 \mathrm{~min}$, then kept at $5{ }^{\circ} \mathrm{C}$. Small, air-stable, green crystals of pure $\mathrm{PPN}\left[\mathrm{FeCl}_{3}(\mathrm{NO})\right]$ formed at the liquid:gas interface in the course of several months (39\% yield with respect to $\mathrm{Fe})$.

\section{Towards a standard route to $\mathrm{A}\left[\mathrm{FeCl}_{2}(\mathrm{NO})_{2}\right]$}

$\mathrm{PPN}\left[\mathrm{FeCl}_{2}(\mathrm{NO})_{2}\right]$ was prepared by a rather laborious procedure starting from $\mathrm{PPN}\left[\mathrm{Fe}(\mathrm{CO})_{3}(\mathrm{NO})\right]$ via $\mathrm{PPN}\left[\mathrm{Fe}(\mathrm{NO})_{2}\left(\mathrm{NO}_{2}-\kappa O\right)_{2}\right]$. Attempts to provide a facile route similar to that for the corresponding MNIC remains to be developed. The current status is as follows.

In a Schlenk flask, a mixture of ferrous chloride tetrahydrate $(119 \mathrm{mg}, 0.60 \mathrm{mmol}, 1 \mathrm{eq}$.$) and$ tetramethylammonium fluoride (112 mg, $1.20 \mathrm{mmol}, 2$ eq.) was dissolved in deoxygenated methanol (3 $\mathrm{mL})$ to a faint yellow solution ( $\mathrm{pH} \approx 3-4)$. The solution was treated with gaseous $\mathrm{NO}$ at room temperature for $2-$ $10 \mathrm{~min}$ and the solution turned brown immediately. Brown-red, air-stable crystals formed at the liquid:gas interface in the course of about a month ( $30 \%$ yield with respect to $\mathrm{Fe})$.

\section{Bromido and Iodido derivatives}

Towards a ferrous route to $\mathrm{A}\left[\mathrm{FeBr}_{3}(\mathrm{NO})\right]$ salts

A mixture of ferrous bromide $(22 \mathrm{mg}, 0.10 \mathrm{mmol}$ ) and bis(triphenylphosphane)iminium bromide (62 $\mathrm{mg}, 0.10 \mathrm{mmol}$ ) was dissolved in deoxygenated methanol $(3 \mathrm{~mL})$. Hydrobromic acid (mass fraction $w=$ $40 \%, 0.1 \mathrm{~mL}, 0.6 \mathrm{mmol})$ and degassed water $(0.25 \mathrm{~mL})$ were added. The clear brown solution of $\mathrm{pH} \approx 2$ was treated with gaseous $\mathrm{NO}$ at room temperature for 10 minutes. A mixture of green crystals as the major product and brown crystals as side product were obtained in the course of a month on keeping the solution at $5^{\circ} \mathrm{C}$.

\section{Crystallography}

Crystals were selected by using a Leica MZ6 polarisation microscope. Suitable crystals were measured with a Bruker D8 Venture diffractometer using Mo-K $\alpha$ irradiation $(\lambda=0.71073 \AA)$. Multi-scan absorption correction was applied. The structure solutions were carried out by direct methods using SHELXT. The structures were refined by full-matrix least-squares calculations on $F^{2}$ using SHELXL-2014. ${ }^{[4]}$ Crystallographic data for the structures reported in this paper have been deposited with the Cambridge Crystallographic Data Centre as supplementary publication no. CCDC 1866190-1866202; details are collected in the SI. Copies of the data can be obtained free of charge on application to CCDC, 12 Union Road, Cambridge CB21EZ (fax: (+ 44)1223-336-033; e-mail: deposit@ccdc.cam.ac.uk).

\section{Computation}

All calculations were performed with Orca in its versions 3 and $4 .{ }^{[47]}$ Basis sets, mostly def2-TZVP, were used as implemented in Orca as well as dispersion corrections. ${ }^{[48]}$ The polar or ionic environment of the anions of this work was modelled by a COSMO (Orca 3) or CPCM (Orca 4) approach. ${ }^{[4]}$

Standard procedures were used for the CASSCF method. Hence, a second shell was added to the 
active space for the iron atom in case of the MNIC. ${ }^{[31]}$ The inclusion of the rather inactive lone pair at the NO-nitrogen atom to yield a $(9,13)$ AS is justified in the text. CASSCF/NEVPT2 calculations for the identification of excited states used state averaging over the specified roots. Preliminary SORCI calculations were performed on a $(9,8)$ active space (the 7 'Enemark-Feltham electrons' + the nitrogen-lone-pair $=9$ electrons in $5 \mathrm{~d}$ orbitals $+2 \mathrm{NO}-\pi^{*}$ orbitals + the N-lone-pair $=8$ orbitals) and confirmed the order of the assignments made. The SORCI calculation was, however, preliminary since a CPCM model is not currently implemented in Orca 4 (a COSMO approach in Orca 3 was not practicable since SORCI was not parallelised in our local copy of this older version).

In the analysis of the excitations of the DNIC species $\left[\mathrm{FeCl}_{2}(\mathrm{NO})_{2}\right]^{-}$, a second shell for the iron atom went beyond the capability of the computational resources available to us. Since, however, the inclusion of the lone pairs on the nitrogen atoms proved significant for the higher roots, we included them in the active space instead of the $4 \mathrm{~d}$ orbitals for iron.

\section{Physics}

UV-vis spectra were recorded on a Cary 50 (solutions) or Cary 500 (solids) spectrometer. Dry barium sulfate was used for the dilution of solid samples. IR spectra were recorded on a Jasco FT/IR-460 Plus Fourier infared spectrometer; the ReactIR investigation was performed on a Mettler Toledo Model 15 spectrometer.

UV-vis spectra were Gauss-deconvoluted by means of the nonlinear least-squares MarquardtLevenberg algorithm implemented in Gnuplot (version 5.2, http://gnuplot.sourceforge.net/). Magnetic measurements were performed on a SQUID magnetometer by Prof. Birgit Weber at the University of Bayreuth, and by the Jorendt group at LMU Munich.

In the course of PLI experiment, infrared spectra were collected on a Nicolet 5700 FTIR spectrometer in the range 4000-360 $\mathrm{cm}^{-1}$ with a resolution of $2 \mathrm{~cm}^{-1}$. The sample was mixed with $\mathrm{KBr}$ (spectroscopy grade), finely ground, and pressed to pellets. The pellets were glued with silver paste to a copper sample holder on the cold finger of an Oxford Optistat V01, allowing temperature regulation in the range 9-300 K. $\mathrm{KBr}$ windows allow for in-situ irradiation of the sample in the ultraviolet, visible and near infrared spectral range.

\section{Conclusions}

Many routes to the simple chlorido-MNIC $\left[\mathrm{FeCl}_{3}(\mathrm{NO})\right]^{-}$, an $\{\mathrm{FeNO}\}^{7}$ species of the $S=3 / 2 \mathrm{branch}$, and its bromido homologue have been published in the last century, most of them leading to characteristic impurities. We have demonstrated that recrystallisation as the standard procedure to obtain pure substances is hampered for crystallographic reasons. Pure samples, as needed for the investigation of physical properties, thus depended on synthetic routes that avoid the formation of unseparable side products. Structure analyses on pure, green crystals with various counterions provided reliable atomic distances and bond angles which served as an entry to computational work on this prototypical anion. Its simple six-atom situation allowed for a higher-level treatment which included the assignment of the vis spectrum by wave-function methods. As a result, all absorption bands of the visible region belong to one of two classes: Fe-NO bond to metal, or metal to $\mathrm{Fe}-\mathrm{NO}$ antibond. For photophysical experiments this means that irradiation into each band, even into the low-energy absorption, weakens the $\mathrm{Fe}-\mathrm{NO}$ bond and, thus, may give rise to linkage isomerism or photolysis. Formulated as a recommendation for photo experiments on a certain material this simply means: 
'irradiate into the highest absorption band, irrespective of its wavelength'.

The first two absorption bands in the order of increasing energy (A and B in Figure 12 and Figure 13) are a typical feature of quartet- $\{\mathrm{FeNO}\}^{7}$ species in general - including the so-called 'brown ring' chromophore, the $\left[\mathrm{Fe}\left(\mathrm{H}_{2} \mathrm{O}\right)_{5}(\mathrm{NO})\right]^{2+}$ ion. ${ }^{[38 \mathrm{a}]}$ These two absorptions, which contribute most to the visible, mostly green, colour of a quartet- $\{\mathrm{FeNO}\}^{7}$ chromophore, both stem from the excitation of a $\beta$-spin electron of the $\mathrm{Fe}-\mathrm{NO} \pi$-bonds to the three singly occupied metal-centered MOs of the quartet species. Taking into account the higher ligand share within the donor MOs, some LMCT character may be assigned to these transitions.

The reaction pathways of a special class of 'side product', the DNICs, frequently cross the routes of the respective MNIC. From a synthetical viewpoint, DNIC formation, both attempted and unintentional, has to be thoroughly controlled. The decisive steering parameters are the presence or absence of base as well as the overall stoichiometry of the reaction batches. It should be noted that the investigation of MNIC/DNIC conversion (as well as the reduction of ferric species by NO) is also a lively area of research for nitrogencoligands, as has been recently demonstrated by the Lehnert group. ${ }^{[22]}$

As a guide to the investigation of tentative photoinduced linkage isomerism (PLI) on MNIC species, a relaxed surface scan predicted the non-exsistence of a side-on-nitrosyl (MS2) PL isomer as well as a, hopefully, tangible isonitrosyl (MS1) species which, however, should not be protected by considerable activation barriers. In fact, a PLI study at a temperature of $9 \mathrm{~K}$ revealed an MS1 isomer. Moreover, this study provides evidence for PLI in the rare case of a paramagnetic nitrosyl-metal coordination entity. In addition, a second excitation process is active in $\mathrm{Mephaz}_{2}\left[\mathrm{FeCl}_{3}(\mathrm{NO})\right]$ which becomes the sole process in the PPN analogue, namely a tentative one-electron charge transfer from the anion to the counterion corresponding to $\mathrm{PPN}^{+}\left[\mathrm{FeCl}_{3}(\mathrm{NO})\right]^{-} \rightarrow \mathrm{PPN}^{\cdot}\left[\mathrm{FeCl}_{3}(\mathrm{NO})\right]$ under formation of an obviously triplett- $\{\mathrm{FeNO}\}^{6}$ transient species.

The principal qualification for PL-isomerism of the respective DNICs was demonstrated for two salts of the $\mathrm{A}\left[\mathrm{FeCl}_{2}(\mathrm{NO})_{2}\right]$ type. As a prerequisite, the UV-vis spectra of the ground-state forms were recorded and analysed. As with the MNIC analogue, these measurements provide the NIC field of research with electronic spectra of the parent nitrosyl-iron moiety without the interfering absorptions of chromogenic coligands. The result should be taken in the sense of a working hypothesis since spin-forbidden transitions seem to gain intensity by some borrowing mechanism. With the DNIC chromophore in particular, still higher-level methods than those available to us should be applied in future work.

Irradiation with visible light created isonitrosyl states at a low population level in all the reported cases. A low population at a very low temperatur together with, more or less, rapid relaxation of the excited states may make the reader ask for the benefit of such investigations. The answer to this question lies, in our eyes, not in the field of photoactive-material synthesis but in the gaining of knowledge of photophysical events, such as the formation of PL-isomers in the course of reaction sequences of species as significant as the MNICs and DNICs.

\section{Acknowledgements}

We are indebted to Professor Birgit Weber (University Bayreuth) and Professor Dirk Johrendt (LMU Munich) for magnetic measurements, and to Professor Hans-Christian Böttcher (LMU Munich) for checking the Connelly/Gardner procedure. We thank Aaron Gerwien for his enthusiastic work on this topic in connection with his research internship.

The authors gratefully acknowledge financial support from the DFG priority program SPP1740 (KL 
624/18-1), aimed at the "influence of local transport processes in chemical reactions in bubble flows".

\section{Conflict of interest}

The authors declare no conflict of interest.

\section{Keywords}

Nitrosyl Complexes, Photo-Induced Isomerism, Iron, Halogenido Coligands, CASSCF Calculations

[1] P. Coppens, I. Novozhilova, A. Kovalevsky, Chem. Rev. 2002, 102, 861-884.

[2] a) D. Schaniel, T. Woike, C. Merschjann, M. Imlau, Physical Review B 2005, 72, 195119/195111195119/195115; b) D. Schaniel, M. Nicoul, T. Woike, PCCP 2010, 12, 9029-9033; c) A. A. Raheem, M. Wilke, M. Borgwardt, N. Engel, S. I. Bokarev, G. Grell, S. G. Aziz, O. Kühn, I. Y. Kiyan, C. Merschjann, E. F. Aziz, Structural Dynamics 2017, 4, 044031; d) J. S. García, F. Alary, M. Boggio-Pasqua, I. M. Dixon, J.-L. Heully, J. Mol. Model. 2016, 22, 284.

[3] N. Xu, J. Yi, G. B. Richter-Addo, Inorg. Chem. 2010, 49, 6253-6266.

[4] L. Cheng, I. Novozhilova, C. Kim, A. Kovalevsky, K. A. Bagley, P. Coppens, G. B. Richter-Addo, J. Am. Chem. Soc. 2000, 122, 7142-7143.

[5] C. F. Sheu, C. H. Shih, K. Sugimoto, B. M. Cheng, M. Takata, Y. Wang, Chem. Commun. 2012, 48, $5715-5717$.

[6] a) M. Wolf, P. Klüfers, Eur. J. Inorg. Chem. 2017, 2303-2312; b) B. M. Aas, P. Klüfers, Eur. J. Inorg. Chem. 2017, 2313-2320.

[7] a) M.-L. Tsai, C.-C. Tsou, W.-F. Liaw, Acc. Chem. Res. 2015, 48, 1184-1193; b) J. Fitzpatrick, E. Kim, Acc. Chem. Res. 2015, 48, 2453-2461; c) A. Buet, M. Simontacchi, Ann. N.Y. Acad. Sci. 2015, 1340, 39-46.

[8] a) V. Kohlschütter, M. Kutscheroff, Ber. Dtsch. Chem, Ges. 1904, 37, 3044-3052; b) S. Begel, R. Puchta, J. Sutter, F. W. Heinemann, L. Dahlenburg, R. v. Eldik, Inorg. Chem. 2015, 54, 6763-6775.

[9] V. Kohlschütter, M. Kutscheroff, Ber. Dtsch. Chem, Ges. 1907, 40, 873-878.

[10] V. Kohlschütter, P. Sazanoff, Ber. Dtsch. Chem, Ges. 1911, 44, 1423-1432.

[11] W. Manchot, Justus Liebigs Ann. Chem. 1910, 372, 179-186.

[12] W. Manchot, E. Linckh, Ber. Dtsch. Chem. Ges. 1926, 59, 406-411.

[13] W. P. Griffith, J. Lewis, G. Wilkinson, J. Chem. Soc. 1958, 3993-3998.

[14] C. C. McDonald, W. D. Phillips, H. F. Mower, J. Am. Chem. Soc. 1965, 87, 3319-3326.

[15] D. Gwost, K. G. Caulton, Inorg. Chem. 1973, 12, 2095-2099.

[16] G. Martini, E. Tiezzi, Trans. Faraday Soc. 1971, 67, 2538-2547.

[17] N. G. Connelly, C. Gardner, J. Chem. Soc., Dalton Trans. 1976, 1525-1527.

[18] H. Akutsu, J.-i. Yamada, S. i. Nakatsuji, S. S. Turner, X-ray Structure Analysis Online 2014, 30, 4950.

[19] E. Victor, S. Kim, S. J. Lippard, Inorg. Chem. 2014, 53, 12809-12821. 
[20] A. M. Tondreau, J. M. Boncella, Polyhedron 2016, 116, 96-104.

[21] T. R. Bryar, D. R. Eaton, Can. J. Chem. 1992, 70, 1917-1926.

[22] A. L. Speelman, B. Zhang, A. Silakov, K. M. Skodje, E. E. Alp, J. Zhao, M. Y. Hu, E. Kim, C. Krebs, N. Lehnert, Inorg. Chem. 2016, 55, 5485-5501.

[23] M. Steimann, U. Nagel, R. Grenz, W. Beck, J. Organomet. Chem. 1983, 247, 171-174.

[24] W. Beck, R. Grenz, F. Götzfried, E. Vilsmaier, Chem. Ber. 1981, 114, 3184-3187.

[25] D. Ballivet-Tkatchenko, M. Riveccie, N. El Murr, J. Am. Chem. Soc. 1979, 101, 2763-2765.

[26] I. N. Levine, Quantum chemistry, Pearson, Boston, 2014, p. 526.

[27] a) T. Clark, in The Chemical Bond, Vol. 2 (Eds.: G. Frenking, S. Shaik), Wiley-VCH, Weinheim, 2014, pp. 523-536; b) T. Clark, Faraday Discuss. 2017, 203, 9-27.

[28] U. Müller, Acta Crystallogr., Sect. B, 1980, 36, 1075-1081.

[29] M. Radoń, E. Broclawik, K. Pierloot, J. Phys. Chem. B 2010, 114, 1518-1528.

[30] A. Bauer Christoph, A. Hansen, S. Grimme, Chem. Eur. J. 2017, 23, 6150-6164.

[31] B. O. Roos, R. Lindh, P. A. Malmqvist, V. Veryazov, P.-O. Widmark, John Wiley \& Sons, Inc., 2016.

[32] J. E. M. N. Klein, B. Miehlich, M. S. Holzwarth, M. Bauer, M. Milek, M. M. Khusniyarov, G. Knizia, H.J. Werner, B. Plietker, Angew. Chem. 2014, 126, 1820-1824.

[33] a) N. Taguchi, Y. Mochizuki, T. Ishikawa, K. Tanaka, Chem. Phys. Lett. 2008, 451, 31--36; b) J. Ivanic, M. W. Schmidt, B. Luke, J. Chem. Phys. 2012, 137, 214316; c) H. Hoshina, M. Slipchenko, K. Prozument, D. Verma, M. W. Schmidt, J. Ivanic, A. F. Vilesov, The Journal of Physical Chemistry A 2016, $120,527-534$.

[34] J. Conradie, K. H. Hopmann, A. Ghosh, J. Phys. Chem. B 2010, 114, 8517-8524.

[35] S. Ye, F. Neese, J. Am. Chem. Soc. 2010, 132, 3646-3647.

[36] F. Neese, J. Phys. Chem. Solids 2004, 65, 781-785.

[37] R. Shannon, Acta Crystallogr., Sect. A, 1976, 32, 751-767.

[38] a) A. Wanat, T. Schneppensieper, G. Stochel, R. van Eldik, E. Bill, K. Wieghardt, Inorg. Chem. 2002, 41, 4-10; b) S. Begel, F. W. Heinemann, G. Stopa, G. Stochel, R. van Eldik, Inorg. Chem. 2011, 50, 39463958.

[39] G. Schenk, M. Y. M. Pau, E. I. Solomon, J. Am. Chem. Soc. 2004, 126, 505-515.

[40] N. L. Fry, X. P. Zhao, P. K. Mascharak, Inorg. Chim. Acta 2011, 367, 194-198.

[41] D. Schaniel, T. Woike, L. Tsankov, M. Imlau, Thermochim. Acta 2005, 429, 19-23.

[42] a) K. Boguslawski, C. R. Jacob, M. Reiher, J. Chem. Theory Comput. 2011, 7, 2740-2752; b) K. Boguslawski, K. H. Marti, Ö. Legeza, M. Reiher, J. Chem. Theory Comput. 2012, 8, 1970-1982; c) K. Boguslawski, P. Tecmer, Ö. Legeza, M. Reiher, J. Phys. Chem. Lett. 2012, 3, 3129-3135.

[43] D. Schaniel, T. Woike, PCCP 2009, 11, 4391-4395.

[44] M. Dennehy, O. V. Quinzani, S. D. Mandolesi, J. A. Güida, G. A. Echeverría, O. E. Piro, Monatshefte für Chemie - Chemical Monthly 2007, 138, 669-675. 
[45] A. L. Speelman, B. Zhang, C. Krebs, N. Lehnert, Angew. Chem. Int. Ed. 2016, 55, 6685-6688.

[46] a) G. M. Sheldrick, Acta Crystallogr., Sect. A, 2015, 71, 3-8; b) G. Sheldrick, Acta Crystallogr., Sect. C, 2015, 71, 3-8.

[47] F. Neese, Wiley Interdisciplinary Reviews: Computational Molecular Science 2012, 2, 73-78.

[48] a) A. Schafer, C. Huber, R. Ahlrichs, J. Chem. Phys. 1994, 100, 5829-5835; b) S. Grimme, J. Antony, S. Ehrlich, H. Krieg, J. Chem. Phys. 2010, 132, 154104-154119.

[49] a) S. Sinnecker, A. Rajendran, A. Klamt, M. Diedenhofen, F. Neese, J. Phys. Chem. A 2006, 110, 2235-2245; b) V. Barone, M. Cossi, J. Phys. Chem. A 1998, 102, 1995-2001. 